\title{
The IncRNA MIR2052HG regulates ERa levels and aromatase inhibitor resistance through LMTK3 by recruiting EGR1
}

Junmei Cairns ${ }^{1}$, James N. Ingle², Krishna R. Kalari ${ }^{3}$, Lois E. Shepherd ${ }^{4}$, Michiaki Kubo ${ }^{5}$, Matthew P. Goetz ${ }^{2}$, Richard M. Weinshilboum ${ }^{1}$ and Liewei Wang ${ }^{1 *}$

\begin{abstract}
Background: Our previous genome-wide association study using the MA.27 aromatase inhibitors adjuvant trial identified SNPs in the long noncoding RNA MIR2052HG associated with breast cancer-free interval. MIR2052HG maintained ERa both by promoting AKT/FOXO3-mediated ESR1 transcription and by limiting ubiquitin-mediated ERa degradation. Our goal was to further elucidate MIR2052HG's mechanism of action.

Methods: RNA-binding protein immunoprecipitation assays were performed to demonstrate that the transcription factor, early growth response protein 1 (EGR1), worked together with MIR2052HG to regulate that lemur tyrosine kinase-3 (LMTK3) transcription in MCF7/AC1 and CAMA-1 cells. The location of EGR1 on the LMTK3 gene locus was mapped using chromatin immunoprecipitation assays. The co-localization of MIR2052HG RNA and the LMTK3 gene locus was determined using RNA-DNA dual fluorescent in situ hybridization. Single-nucleotide polymorphisms (SNP) effects were evaluated using a panel of human lymphoblastoid cell lines.

Results: MIR2052HG depletion in breast cancer cells results in a decrease in LMTK3 expression and cell growth. Mechanistically, MIR2052HG interacts with EGR1 and facilitates its recruitment to the LMTK3 promoter. LMTK3 sustains ERa levels by reducing protein kinase C (PKC) activity, resulting in increased ESR1 transcription mediated through AKT/FOXO3 and reduced ERa degradation mediated by the PKC/MEK/ERK/RSK1 pathway. MIR2052HG regulated LMTK3 in a SNP- and aromatase inhibitor-dependent fashion: the variant SNP increased EGR1 binding to LMTK3 promoter in response to androstenedione, relative to wild-type genotype, a pattern that can be reversed by aromatase inhibitor treatment. Finally, LMTK3 overexpression abolished the effect of MIR2052HG on PKC activity and ERa levels.

Conclusions: Our findings support a model in which the MIR2052HG regulates LMTK3 via EGR1, and LMTK3 regulates ERa stability via the PKC/MEK/ERK/RSK1 axis. These results reveal a direct role of MIR2052HG in LMTK3 regulation and raise the possibilities of targeting MIR2052HG or LMTK3 in ERa-positive breast cancer.
\end{abstract}

Keywords: Lon noncoding RNA, MIR2052HG, EGR1, LMTK3, PKC, ERa, Aromatase inhibitor

\footnotetext{
* Correspondence: wang.liewei@mayo.edu

${ }^{1}$ Department of Molecular Pharmacology and Experimental Therapeutics,

Mayo Clinic, Rochester, MN 55905, USA

Full list of author information is available at the end of the article
}

(c) The Author(s). 2019 Open Access This article is distributed under the terms of the Creative Commons Attribution 4.0 International License (http://creativecommons.org/licenses/by/4.0/), which permits unrestricted use, distribution, and reproduction in any medium, provided you give appropriate credit to the original author(s) and the source, provide a link to the Creative Commons license, and indicate if changes were made. The Creative Commons Public Domain Dedication waiver (http://creativecommons.org/publicdomain/zero/1.0/) applies to the data made available in this article, unless otherwise stated. 


\section{Background}

Estrogens have long been recognized to be important for stimulating the growth of estrogen receptor $\alpha(E R \alpha)$-positive breast cancer, a subtype that represents a large proportion of breast cancer patients. Estrogen action is mediated by ER $\alpha$. Approximately $70 \%$ of breast cancers are ER $\alpha$ positive and rely on estrogen signaling to stimulate their growth and survival $[1,2]$. Its presence in breast tumors is routinely used to predict response to endocrine therapies that target $\mathrm{ER} \alpha$, estrogen production or estrogen signaling. Aromatase inhibitors (AIs) suppress estrogen synthesis in postmenopausal women by targeting the aromatase enzyme, which converts precursor hormones to estrogens. The third-generation AIs (i.e., exemestane, anastrozole, and letrozole) have largely replaced tamoxifen as the preferred treatment for ER $\alpha$-positive breast cancer in postmenopausal women with early-stage breast cancer because of their superior efficacy over tamoxifen [3, 4]. However, both de novo and acquired resistance to AIs can occur, resulting in relapse and disease progression. It is estimated that approximately $30 \%$ of ER-positive breast cancer receiving adjuvant AI treatment eventually develop resistance [57], while nearly all patients develop resistance in the metastatic setting. The mechanisms for endocrine therapy resistance are complex and one mechanism includes dysregulation of ER $\alpha$ expression, encoded by ESR1 [8].

$E R \alpha$ is a member of the nuclear receptor superfamily of ligand-activated transcription factors [9], which regulates gene expression through direct binding to estrogen response elements (EREs) in promoters of estrogen-regulated genes and indirectly through recruitment to gene promoters by interaction with other transcription factors [10]. Previous studies have reported that ESR1 is upregulated during estrogen deprivation adaptation [11]. Overproduction of ER $\alpha$ leads to an enhanced response to low concentrations of estrogen, which is responsible for the acquisition of AI resistance or postmenopausal tumorigenesis [12, 13]. In these AI-resistant tumors, ER $\alpha$ is hypersensitive to low levels of estrogens [14] activated in a ligand-independent manner either by phosphorylation via kinases in the growth factor receptor signaling pathways or by acquired somatic ESR1 mutations [15, 16]. ER $\alpha$ phosphorylation aids in regulating the transcriptional activity and turnover of ER $\alpha$ by proteasomal degradation. Of particular importance are Ser118 and Ser167, which locate within the activation function 1 region of the $\mathrm{N}$-terminal domain of $E R \alpha$ and are regulated by multiple signaling pathways [17-20]. The phosphorylation at Ser118 can be mediated by mitogen-activated protein kinase (MAPK) activation and induces ER $\alpha$ activity $[15,21]$, whereas Ser167 can be phosphorylated by p90RSK $[22,23]$ and plays a role in lemur tyrosine kinase 3 (LMTK3)-mediated ER $\alpha$ stabilization [24, 25]. LMTK3 has been implicated in both de novo and acquired endocrine resistance in breast cancer [26]. The phosphorylation of ER $\alpha$ at S167 is positively associated with pMAPK and pp90RSK in breast cancer patients and a predictor of better prognosis in primary breast cancer with reduced relapse and better overall survival [27].

Our previous genome-wide association study (GWAS) used samples from the Canadian Cancer Trials Group MA.27, the largest AI breast cancer adjuvant endocrine therapy trial (4406 controls without recurrence of breast cancer and 252 cases with recurrence). In that study, we identified common single-nucleotide polymorphisms (SNPs) in a long noncoding (lnc) RNA, MIR2052HG, that were associated with breast cancer free interval $(\mathrm{HR}=0.37$, $p=2.15 \mathrm{e}-07$ ) [28]. The variant SNPs (minor allele frequency $[\mathrm{MAF}]=0.32$ to 0.42 ) were associated with lower MIR2052HG and ER $\alpha$ expression in the presence of AIs, and two of the top SNPs, rs4476990 and rs3802201, were located in or near an ERE [28]. MIR2052HG appeared to affect ER $\alpha$ expression both by promoting AKT/FOXO3-mediated ESR1 transcription regulation and by limiting ubiquitin-mediated ER $\alpha$ degradation [28]. However, the underlying mechanisms by which MIR2052HG regulates ESR1 transcription and ER $\alpha$ degradation remain unknown.

Long noncoding RNA (lncRNAs) are transcripts with no protein-coding functions. Accumulating evidence suggests that lncRNAs play critical roles in regulating a wide range of cellular processes through affecting various aspects of protein, DNA, and RNA expression and interactions [29-31]. Several lncRNAs have been implicated in breast cancer. For example, UCA1 is an oncogene in breast cancer that can induce tamoxifen resistance [32]. LncRNA HOTAIR is positively correlated with tamoxifen resistance [33]. In the current study, we sought to further investigate the mechanism of MIR2052HG action in the regulation of ER $\alpha$ and AI resistance. We found that MIR2052HG directly interacts with the early growth response protein 1 (EGR1) protein to enhance LMTK3 transcription and thus sustained ESR1 expression and stabilized ER $\alpha$ protein.

\section{Methods}

\section{Cell lines and chemical reagents}

Human ER-positive breast cancer CAMA-1, HER-positive Au565, triple negative breast cancer (TNBC) MDA-MB-231, and human embryonic kidney cell line $293 \mathrm{~T}$ cell lines were obtained from American Type Culture Collection (ATCC). The identities of all cell lines were confirmed by the medical genome facility at Mayo Clinic Center (Rochester MN) using short tandem repeat profiling upon receipt. The breast cancer MCF7/AC1 cell line (stably transfected CYP19A1 gene) was provided by Dr. Angela Brodie (University of Maryland, Baltimore, 
MD). The cells were authenticated in 2015 by Genetica DNA Laboratories (Cincinnati, OH) using a StemElite ID system that uses short tandem repeat genotyping. CAMA-1cells were cultured in EMEM media (Eagle's minimum essential medium) (ATCC) with $10 \%$ fetal bovine serum (FBS) (Corning) and MCF7/AC1 cells were cultured in IMEM (Improved MEM, no phenol red) (Life Technologies) with $10 \%$ heated inactive FBS in the incubator with $5 \% \mathrm{CO}_{2}$ at $37^{\circ} \mathrm{C}$. $293 \mathrm{~T}$ cells were cultured in Dulbecco's modified Eagle's medium (Life Technologies) with 10\% FBS, and Au565 cells were cultured in RPMI-1640 (Life Technologies) with 10\% FBS in the incubator with $5 \% \mathrm{CO}_{2}$ at $37^{\circ} \mathrm{C}$. MDA-MB-231 cells were cultured in L-15 medium with $10 \%$ FBS in the incubator without $\mathrm{CO}_{2}$. Five lymphoblastoid cell lines (LCLs) with MIR2052HG wild-type (WT) SNPs and five LCLs with MIR2025HG variant SNPs were selected. Before androstenedione treatment, $\sim 2 \times 10^{7}$ cells from each LCL were cultured in RPMI-1640 media containing 5\% charcoal stripped FBS (Invitrogen) for $24 \mathrm{~h}$, followed with RPMI-1640 medium without FBS for additional $24 \mathrm{~h}$. Each LCL was plated into 12-well plates with RPMI-1640 medium containing $0.01,0.1,1$, and $10 \mathrm{nM}$ androstenedione. After $24 \mathrm{~h}$ treatment, increasing concentrations of anastrozole or exemestane were added. The anastrozole and exemestane concentrations ranged from $0.1,1,10$, to $100 \mathrm{nM}$. After an additional $24 \mathrm{~h}$, all LCLs were collected for further RNA extraction and qRT-PCR.

Anastrozole and exemestane (Selleckchem) were dissolved in DMSO (Sigma-Aldrich) as $100 \mathrm{mM}$ stock. 4-Androstene-3, 17-dione (Steraloids Inc.) was dissolved in $100 \%$ ethanol. FLAG-ER $\alpha$ plasmid was provided by Thomas Spelsberg, Ph.D. (Mayo Clinic). FLAG-ER $\alpha$ S167A mutant was generated from the FLAG-ER $\alpha$ plasmid using QuickChange Site Directed Mutagenesis kit (Agilent). HA-Ub plasmid was provided by Zhenkun Lou, Ph.D. (Mayo Clinic). LMTK3 plasmid was purchased from Origene. Protein kinase C (PKC) inhibitor, Go 6983, was purchased from Sigma. Antibodies against GAPDH, AKT, p-AKT (Ser473), FOXO3, EGR1, EZH2, RSK1, pRSK1, ERK1/2, p-ERK1/2, MEK1/2, p-MEK1/2, and Phospho-(Ser) PKC Substrate Antibody were purchased from Cell Signaling. ER $\alpha$ and ER $\alpha$-S167 antibodies were obtained from Abcam. LMTK3, BHLHE40, CTCF, EP300, HDAC6, POLR2A, REST, CREBBP, YY1, STAT1, and SNRNP70 antibodies were purchased from Santa Cruz. CHD2 antibody was from Thermo Fisher Scientific. Secondary HRP (horseradish peroxidase)-conjugated anti-rabbit IgG and anti-mouse IgG antibodies were from Cell Signaling.

\section{Antisense oligo knockdown and CDNA construct overexpression}

Antisense oligonucleotides (ASOs) were used to knockdown and study the functions of MIR2052HG. Pools of two ASOs for MIR2052HG produced with locked nucleic acids modification of $5^{\prime}$ and $3^{\prime}$ ends (Exiqon) were validated previously [28]. Negative control ASO was obtained from Exiqon. Lipofectamine RNAi Max (Invitrogen) and OPTI-MEM (Life Technologies) were used for ASOs transfection. Knockdown efficiency was measured using TaqMan qRT-PCR. The sequences of ASOs were as follows: ASO1: 5'-GTTGATTAGATTTGG-3'; ASO2: 5'-ACAGTCCCGATCTTC-3'; negative control: 5' -AACA CGTCTATACGC-3'. LMTK3 plasmids (Origene) were transfected into cells using Lipofectamine 2000 reagent (Thermo Fisher Scientific). Total RNA was extracted $48 \mathrm{~h}$ after transfection for RNA quantification. Whole cell lysates were collected $48 \mathrm{~h}$ after transfection for western blots.

\section{Quantitative real-time PCR assay (qRT-PCR)}

QRT-PCR assays were performed for measuring gene expression using the TaqMan RNA-to-Ct 1-Step Kit (Life Technologies). RNA was extracted using the miRNeasy mini Kit (Qiagen). RNA was measured by NanoDrops300. The TaqMan primers for MIR2052HG, ESR1, and GAPDH were purchased from Life Technologies. Primers for EGR1 targeted genes and ESR1 targeted genes were purchased from IDT. QRT-PCR reactions were prepared following the manufacturer's protocol. Samples were run using the StepOnePlus real-time PCR system (ABI).

\section{Western blotting}

Cells were washed with cold PBS and were lysed in cold NETN buffer $(100 \mathrm{mM} \mathrm{NaCl}, 20 \mathrm{mM}$ Tris $\cdot \mathrm{HCl} \mathrm{pH}=0.8$, 0.5 mM EDTA, NP-40) with proteasome cocktail inhibitor and phosphatase inhibitor PhosSTOP EASY. Cell lysates were diluted with SDS loading buffer (SDS, glycerol, bromic acid, $1 \mathrm{M}$ Tris. $\mathrm{HCl}$ ) and boiled, centrifuged at $10,000 \mathrm{rpm}$, and stored at $-20^{\circ} \mathrm{C}$. Equal amounts of protein were subjected to electrophoresis in TGX SDS gels and were transferred to PVDF membranes. Membranes were blocked in TBS with 5\% BSA and $0.1 \%$ Tween-20 and then incubated overnight at $4{ }^{\circ}$ $\mathrm{C}$ with the indicated primary antibodies. Membranes were washed with TBS-T (TBS with $0.1 \%$ Tween-20) and then incubated with anti-mouse IgG or anti-rabbit IgG for $1 \mathrm{~h}$ at room temperature. All blots were visualized with the Supersignal WestPico or Supersignal WestDura chemiluminescent ECL kits (Thermo Fisher) and blue X-ray films or Gel Doc XR+ Gel documentation system (Biorad).

\section{RNA-seq analysis and normalization}

RNA was prepared from MCF7/AC1 cells using the TRIzol extraction kit (Life Technologies). Genomic DNA was removed using the Ambion DNA-free kit. NuGEN Encore reagents were used for library preparation of 
total RNA samples. One microgram of total RNA input was used for each sample. The libraries were sequenced on an Illumina HiSeq 2000 sequencing system using 100-bp single-ended reads. After removing the poor-quality bases from FASTQ files for the whole transcriptome sequencing, paired-end reads were aligned by reads that were aligned to the human reference genome UCSC hg19 with Tophat 2.0.14 and the bowtie 2.2.6 aligner option. Transcript abundance was estimated using a count-based method with htseq-count.

\section{Cell proliferation and cell survival assays}

Cells were seeded (2000 cells/100 $\mu \mathrm{L} /$ well) in a 96-well plate. The CyQUANT Direct Cell Proliferation Assay kit (Invitrogen) was used to determine the cell viability in six replicates. CyQUANT assays were performed to determine the cell viability every 2 days. Measurements were made using a microplate reader with excitation at $485 \mathrm{~nm}$ and emission detection at $530 \mathrm{~nm}$. Each absorbance was normalized to the media control without any cells.

Cell survival assays were carried out in 96-well plates. Cells were seeded (5000 cells/100 $\mu \mathrm{L} /$ well) in a 96-well plate and treated with AIs for $72 \mathrm{~h}$. CyQUANT assay was used to determine the cell viability in six replicates. Each absorbance was normalized to the media control without any cells.

\section{Colony forming assays}

Cells transfected with MIR2052HG ASOs or LMTK3 plasmids were plated $(800 \sim 1000$ cells/well $)$ in 6-well culture clusters in triplicates. Subsequently, the cells were cultured for up to 14 days at $37^{\circ} \mathrm{C}, 5 \% \mathrm{CO}_{2}$ to allow colony formation. Colonies were washed with cold PBS, fixed with $4 \%$ paraformaldehyde and stained by $0.05 \%$ crystal violet. Colonies ( $>50$ cells) were accounted with the ImageJ software (version 1.42q).

\section{Ubiquitination assays}

Approximately $1.5 \mu \mathrm{g}$ of HA-ubiquintin plasmid and $1.5 \mu \mathrm{g}$ of pcDNA 4.1-ER $\alpha$ plasmid with FLAG tag were co-transfected in HEK $293 \mathrm{~T}$ cells using lipofectamine 2000. Twenty-four hours later, cells were reversely transfected with the MIR2052HG ASO or negative control. Approximately $2 \times 10^{5}$ ASOs transfected and control cells were subsequently seeded into each $60-\mathrm{mm}$ dishes. After $64 \mathrm{~h}, \mathrm{MG} 132$ was added at a final concentration of $10 \mu \mathrm{M}$ for an additional $8 \mathrm{~h}$. Cells were then collected for the ubiquitination assay. Specifically, these cells were washed in cold PBS with NEM (1:100) and lysed in 2\% SDS lysis buffer [62.5 mM Tris. $\mathrm{HCl} \mathrm{pH}=6.8,10 \%$ glycerol $(v / \mathrm{v})$, SDS $2 \%(\mathrm{~g} / \mathrm{v})]$. Immunoprecipitation assays were performed with the anti-FLAG antibody-conjugated gels (Sigma). After washing, the FLAG gels were dissolved in
2xSDS loading buffer and boiled. These samples were then subjected to western blotting using the anti-ubiquitin antibody and anti-FLAG antibody.

\section{PKC kinase assay}

PepTag assay for nonradioactive detection of PKC Activity: MCF7/AC1 and CAMA-1 cells were transfected with indicated ASO or plasmids. Forty-eight hours later, cells were lysed and incubated with PKC reaction mixture $(25 \mu \mathrm{l})$ according to the manufacturer's (Promega) protocol at $30^{\circ} \mathrm{C}$ for $30 \mathrm{~min}$. The reactions were stopped by heating at $95^{\circ} \mathrm{C}$ for $10 \mathrm{~min}$. After adding $80 \%$ glycerol $(1 \mu \mathrm{l})$, phosphorylated and nonphosphorylated PepTag peptides were separated by electrophoresis with $0.8 \%$ agarose gel. The negatively charged phosphorylated bands were excised using a razor blade, placed in a graduated microcentrifuge tube, and heated at $95^{\circ} \mathrm{C}$ until the gel slice melted. The volume of the solution was adjusted to $250 \mu \mathrm{l}$ with water. The hot agarose solution $(125 \mu \mathrm{l})$ was added to a separate tube containing $75 \mu \mathrm{l}$ of gel solubilization solution and $50 \mu \mathrm{l}$ of glacial acetic acid. The absorbency was read at $570 \mathrm{~nm}$. Using the absorbance, we calculated the number of units of kinase activity in each slice of agarose as per the manufacturer's instructions (Promega). Assays were performed in triplicates.

Western Blot analysis of PKC activity was performed using lysates from MCF7/AC1 and CAMA-1 cells transfected with indicated ASO or plasmids. Phosphoserine PKC substrate proteins were detected by incubation overnight at $4{ }^{\circ} \mathrm{C}$ with anti-phosphoserine PKC substrate antibody.

\section{Chromatin immunoprecipitation (ChIP)}

ChIP assays were performed using EpiTect ChIP OneDay kit (Qiagen). MCF7/AC1 and CAMA-1 cells were transfected with MIR2052HG ASO for 24h. Cells were then subjected to ChIP assay as described by the manufacturer. LCLs were cultured in 5\% charcoal stripped FBS for $24 \mathrm{~h}$, followed with serum-free medium for additional $24 \mathrm{~h}$. LCLs were then treated with $1 \mathrm{nM}$ androstenedione, $1 \mathrm{nM}$ androstenedione plus $100 \mathrm{nM}$ anastrozole, and $1 \mathrm{nM}$ androstenedione plus $100 \mathrm{nM}$ exemestane for additional $24 \mathrm{~h}$. Approximately $2 \times 10^{7}$ LCLs per every sample (different SNP genotypes with androstenedione or androstenedione plus anastrozole or exemestane treatment groups) were collected for the ChIP assay. Equal amount of chromatin from each sample $(\sim 2$ million cells each IP) and $1 \mu$ g control IgG or antibody against EGR1 were used. Q-PCR was carried out, and the result was normalized to input. All primers are listed in Additional file 1: Table S1. 


\section{Fluorescent in situ hybridization (FISH)}

The sequential protein staining and RNA detection were performed as previously described [34, 35]. Briefly, the cells were grown in chamber slides. LMTK3 staining was performed as usual until secondary antibody is labeled in the presence of RNase inhibitor. Slides were then dehydrated by serial treatment of ethanol with different concentrations. The Alexa Fluor 488-labeled RNA probe was obtained using the FISH Tag RNA Kit (Invitrogen). In the first step, in vitro transcription is used to enzymatically incorporate an amine-modified nucleotide into the probe template. The modified nucleotide is UTP having an $\mathrm{NH} 2$ group attached through a linker to the $\mathrm{C} 5$ position of the base. In the second step, dye labeling of the purified amine-modified RNA is achieved by incubation with amine-reactive dyes. These active ester compounds react with the primary amines incorporated into the probe template, covalently conjugating the dye to the modified nucleotide base. The purified probe is then ready for hybridization to the specimen slides at $37^{\circ} \mathrm{C}$ overnight. Signal was then amplified using Tyramide Signal Amplification (TSA) kit (Life Technologies). LMTK3 DNA probe was produced using the FISH Tag DNA Kit (Invitrogen). In the first step, nick translation is used to enzymatically incorporate an amine-modified nucleotide into the probe template. The modified nucleotide is dUTP having an NH2 group attached through a linker to the $\mathrm{C} 5$ position of the base. In the second step, dye labeling of the purified amine-modified DNA is achieved by incubation with amine-reactive dyes. These active ester compounds react with the primary amines incorporated into the probe template, covalently conjugating the dye to the modified nucleotide base. The purified probe is then ready for hybridization to the specimen. For dual RNA-DNA-FISH, we used the protocol as previously described [35]. In brief, RNA-FISH was performed by using Nick-translated Alexa Fluor 488-labeled probe and followed by tyramide signal amplification kit as above. After RNA-FISH, the cells were treated by RNase A and denatured. Nick-translated BAC containing LMTK3 was labeled with Alexa Fluor 594 and used as probe. Images were obtained with the LSM 780 inverted confocal microscope runs on Zeiss's Zen software package.

\section{RNA-binding protein immunoprecipitation}

An RNA-binding protein immunoprecipitation (RIP) assay was performed using the Magna RIP kit (Millipore) according to the manufacturer's instruction. Cell lysates from 50 million cells and $2-5 \mu \mathrm{g}$ of control IgG or antibody against BHLHE40, CHD2,
CTCF, EGR1, EP300, EZH2, HDAC6, POLR2A, REST, CREBBP, YY1, and STAT1 were used. We validated the RIP assay using the SNRNP70 antibody, which can bind to U1 snRNA. Specifically, cells were washed on the plates twice with $10 \mathrm{~mL}$ of PBS, scraped off from plate, and centrifuged at $1500 \mathrm{rpm}$ for $5 \mathrm{~min}$ at $4{ }^{\circ} \mathrm{C}$ and discard the supernatant. Cell pellet was re-suspended in an equal pellet volume of complete RIP lysis buffer and then incubated on ice for $5 \mathrm{~min}$. Dispense $\sim 200 \mu \mathrm{L}$ each of the lysate into nuclease-free microcentrifuge tubes and store at $80^{\circ} \mathrm{C}$. Immunoprecipitations were performed using antibodies of interest and IgG control. Anti-SNRNP70 served as controls. Fifty micro liters of magnetic beads was washed and re-suspended in $100 \mu \mathrm{L}$ of the RIP wash buffer. Two to approximately micrograms of the antibody of interest was added to each reaction and incubated with rotation for 30 min. The beads were then washed three times with RIP wash buffer. Nine hundred microliters of RIP immunoprecipitation buffer was then added to each tube. The RIP lysate were thawed and centrifuged at $14,000 \mathrm{rpm}$ for $10 \mathrm{~min}$ at $4{ }^{\circ} \mathrm{C}$, and $100 \mu \mathrm{L}$ of the supernatant was added to each beads-antibody complex in RIP immunoprecipitation buffer. Ten microliters of the supernatant of RIP lysate was removed as " $10 \%$ input" and stored at $-80^{\circ} \mathrm{C}$ until starting RNA purification. The immunoprecipitations were incubated with rotating overnight at $4{ }^{\circ} \mathrm{C}$, followed by six washes with $500 \mu \mathrm{L}$ of cold RIP wash buffer. RNA purification was then performed. Each immunoprecipitate was re-suspended in $150 \mu \mathrm{L}$ of proteinase $\mathrm{K}$ buffer. The input samples were thawed and $107 \mu \mathrm{L}$ of RIP wash buffer, and $15 \mu \mathrm{L}$ of $10 \%$ SDS and $18 \mu \mathrm{L}$ of proteinase $\mathrm{K}$ were added to the tubes. All tubes were incubated at $55^{\circ} \mathrm{C}$ for $30 \mathrm{~min}$ with shaking to digest the protein and then centrifuged briefly before being placed on the magnetic separator. The supernatant was then transferred into a new tube, together with $250 \mu \mathrm{L}$ of RIP wash buffer. Four hundred microliters of phenol to chloroform to isoamyl alcohol was then added to each tube, followed by vortex for $15 \mathrm{~s}$ and centrifugation at $14000 \mathrm{rpm}$ for $10 \mathrm{~min}$ to separate the phases. Three hundred microliters of the aqueous phase was carefully removed and placed in a new tube, together with $400 \mu \mathrm{L}$ of chloroform. After vortex for $15 \mathrm{~s}$ and centrifugation at $14000 \mathrm{rpm}$ for $10 \mathrm{~min}$, the phases were separated. Three hundred microliters of the aqueous phase was carefully removed, and place it in a new tube $50 \mu \mathrm{L}$ of salt solution I, $15 \mu \mathrm{L}$ of salt solution II, $5 \mu \mathrm{L}$ of precipitate enhancer, and $850 \mu \mathrm{L}$ of ethanol were added to each tube and kept at $-80{ }^{\circ} \mathrm{C}$ overnight to precipitate the RNA. The samples were then centrifuged at 
$14,000 \mathrm{rpm}$ for $30 \mathrm{~min}$ at $4{ }^{\circ} \mathrm{C}$. The pellets were washed once with $80 \%$ ethanol, air dried, and re-suspended in 10 to $20 \mu \mathrm{L}$ of RNase-free water. The RNAs were then analyzed by qRT-PCR.

\section{Luciferase activity assay}

Transcription activity of EGR1 was measured using the dual luciferase assay with the Cignal EGR1 Reporter Assay Kit (Qiagen). MIR2052HG knocked-down MCF7/ AC1 and CAMA-1 cells were transfected with either EGR1 reporter (EGR1-responsive GFP reporter), negative control (GFP reporter construct with GFP expression controlled by a minimal promoter), or positive control (constitutively expressing GFP construct) constructs using the Lipofectamine 2000 transfection reagent. After $24 \mathrm{~h}$ of transfection, luciferase assay was performed using the Dual-Glo Luciferase Reporter Assay System (Promega) following the manufacturer's protocol.

\section{Statistical analysis}

For cell survival, cell proliferation, kinase activity, gene expression, and quantifications, data are represented as the mean \pm SEM of three independent experiments. Statistical analyses were performed with Student's $t$ test. Statistical significance is represented in figures by ${ }^{*} p<$ 0.05 and $* * 0.01$.

\section{Results}

\section{MIR2052HG regulates LMTK3 expression}

We previously reported that MIR2052HG sustained ER $\alpha$ levels by promoting AKT/FOXO3-mediated upregulation of ESR1 transcript and by limiting proteasome-dependent degradation of $E R \alpha$ protein [28]. However, the mechanism involved in the regulation of MIR2052HG-mediated AKT activation and $E R \alpha$ ubiquitination remains unknown. Kinome screening previously identified LMTK3 as a potent ER $\alpha$ regulator, acting by decreasing the activity of protein kinase $\mathrm{C}(\mathrm{PKC})$ and the phosphorylation of AKT (Ser473), resulting in increased binding of FOXO3 to the ESR1 promoter [24]. LMTK3 also protected ER $\alpha$ from proteasome-mediated degradation [24]. Given that the effects of LMTK3 on ER $\alpha$ were similar to our observations with MIR2052HG [28], we hypothesized that MIR2052HG might regulate LMTK3 to mediate ER $\alpha$ levels and, in turn, response to AIs.

Previous studies have demonstrated that lncRNAs can function in trans to regulate expression of protein-coding genes; therefore, we examined the possibility that MIR2052HG may facilitate AI resistance by regulating LMTK3 expression. Consistent with this hypothesis, we found that knockdown of MIR2052HG using a pooled ASO in human ER-positive CAMA-1 breast cancer cells resulted in a dramatic decrease of
LMTK3 expression (Fig. 1a). A similar effect was also observed in an aromatase overexpressing cell line, MCF7/AC1 [36] (Fig. 1b). We also observed that the changes in mRNA levels were confirmed at the protein level by the western blot analysis (Fig. 1c), supporting the notion that MIR2052HG regulates LMTK3 expression. To determine whether LMTK3 is a major downstream target of MIR2052HG in regulating AI response, we first determined the transcriptome changes in MIR2052HG-knockdown MCF7/AC1 cells and collected published RNA-seq data after LMTK3-knockdown [26]. Analysis of the RNA-seq data indicated that the changes induced by MIR2052HG knockdown and LMTK3 knockdown showed a large number genes overlapped, especially almost $1 / 3$ genes regulated by LMTK3 were also regulated by MIR2052HG (Fig. 1d, Additional file 2: Table S2). The common dysregulated genes in both knockdowns included cell cycle genes, oocyte maturation, and oocyte meiosis genes (Additional file 2: Table S2).

To further define the relationship between MIR2052HG and LMTK3, we transfected LMTK3 overexpressing constructs into ER $\alpha$-positive breast cancer cells with MIR2052HG-knockdown, followed by cell growth and colony forming assays. The cell proliferation and colony formation analysis demonstrated that the cell growth defect caused by downregulation of MIR2052HG could be successfully rescued by LMTK3 overexpression (Fig. 2ad), indicating that LMTK3 is a major target that mediates the MIR2052HG regulation on cell growth in ER-positive breast cancer.

\section{LMTK3 mediates MIR2052HG-regulation of ESR1 transcription and ERa protein stability}

Previous studies demonstrated that MIR2052HG regulates $E R \alpha$ expression through transcription regulation of ESR1 and ER protein degradation [24, 28]. However, the direct target of MIR2052HG in ER $\alpha$ regulation has not been fully elucidated. Therefore, we examined the role of LMTK3 in ER $\alpha$ regulation. Our previous report indicated that the effect of MIR2052HG on ESR1 transcript is through AKT/ FOXO3 [24]. In MCF7/AC1 and CAMA-1 cells, downregulation of MIR2052HG reduced ESR1 mRNA levels by promoting AKT-mediated downregulation of FOXO3 protein level, a transcription factor known to be involved in ESR1 transcription (Fig. 3a, b). LMTK3 overexpression rescued the downregulation of ER $\alpha$ mRNA induced by MIR2052HG silencing (Fig. 3a, b). LMTK3 overexpression resulted in a decrease in phosphorylated AKT (at Ser473) and an increase in FOXO3 protein level but not mRNA level (Fig. 3a, b, Additional file 3: Figure S1a). At the protein level, ER $\alpha$ protein was reduced by MIR2052HG knockdown, whereas LMTK3 overexpression stabilized ER $\alpha$ 


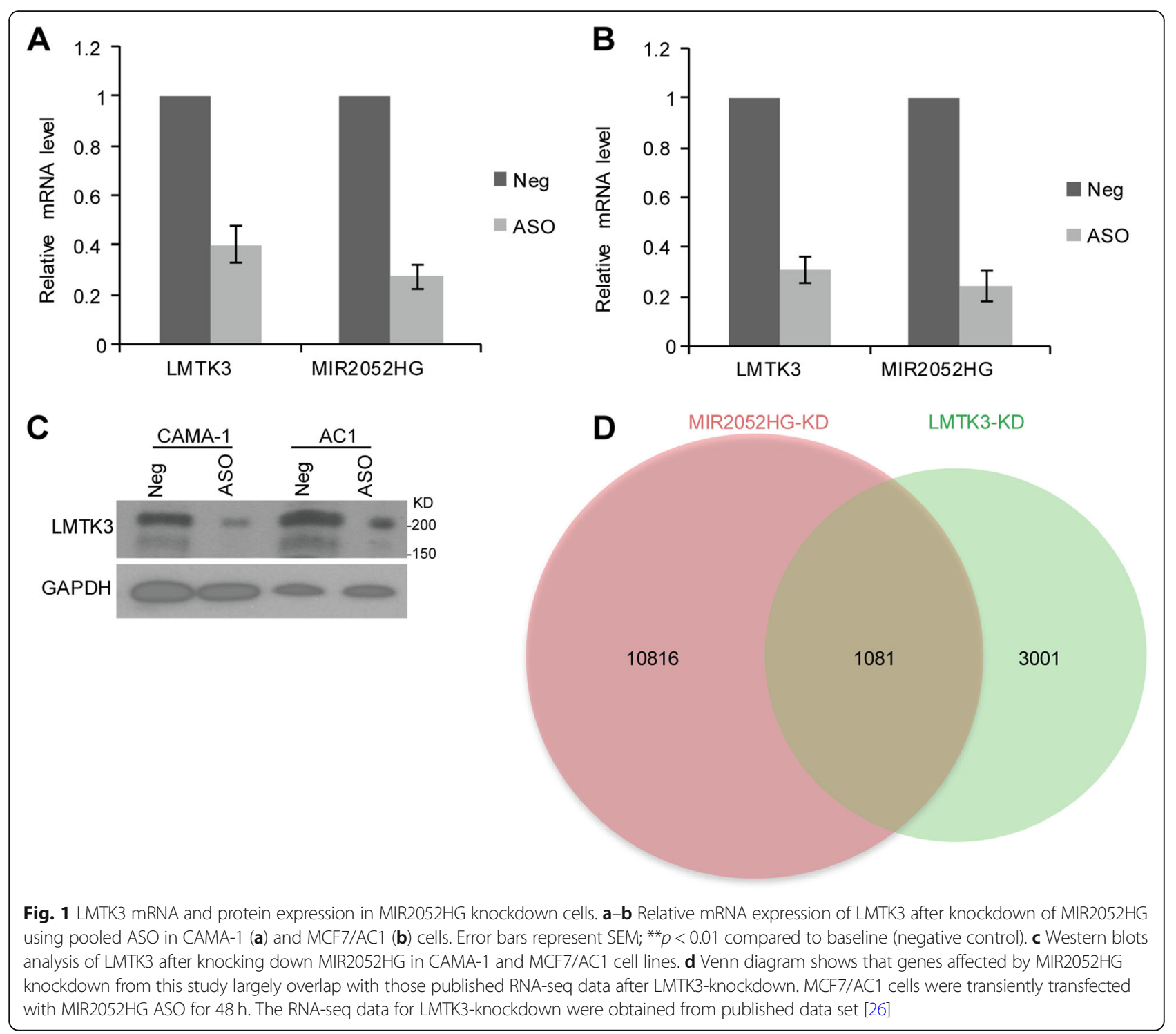

(Fig. 3a, b, right panel). Our previous results showed that MIR2052HG also regulated ER $\alpha$ stability by regulating its proteasome-dependent degradation process. Here, LMTK3 overexpression could increase protein level by decreasing ER $\alpha$ ubiquitination (Fig. 3c). Together, these data indicate that LMTK3, downstream of MIR2025HG, mediated MIR2052HG effect on the regulation of ESR1 transcription and ER $\alpha$ protein stability.

\section{MIR2052HG regulates ERa protein degradation through the LMTK3/PKC/MEK/ERK/RSK1 pathway}

Next, we investigated the mechanisms involved in MIR2052HG and LMTK3 regulation of ER $\alpha$ protein degradation. ER $\alpha$ phosphorylation, especially increased phosphorylation of ER $\alpha$ at Ser167, has been implicated in $E R \alpha$ proteasome-mediated degradation [24]. To explore the mechanism, we first determined the level of ER $\alpha$ pSer167 in MIR2052HG knockdown ER $\alpha$-positive breast cancer cells. ER $\alpha$ pSer167 levels increased with MIR2052HG knockdown, despite decreased total ER $\alpha$ amounts (Fig. 4a). Furthermore, we observed that knocking down MIR2052HG increased wild-type (WT) ER $\alpha$ ubiquitination, but not the mutant ER $\alpha$ with serine 167 to alanine (S167A) (Fig. 4b), confirming the involvement of ER $\alpha$ Ser167 in ubiquitin-dependent and proteasome-mediated degradation. The phosphorylation of ER $\alpha$ at Ser167 is regulated by pp90 (RSK1) [22] which is activated by MAPK [37]. We thus hypothesized that MEK/ERK/p90RSK1 might be the signaling pathway that mediates ER $\alpha$ phosphorylation at Ser167 upon MIR2052HG knockdown. We first tested the effect of knockdown of MIR2052HG on MEK/ERK/p90RSK1 activity. As shown in Fig. 4a, in MCF7/AC1 and CAMA-1 


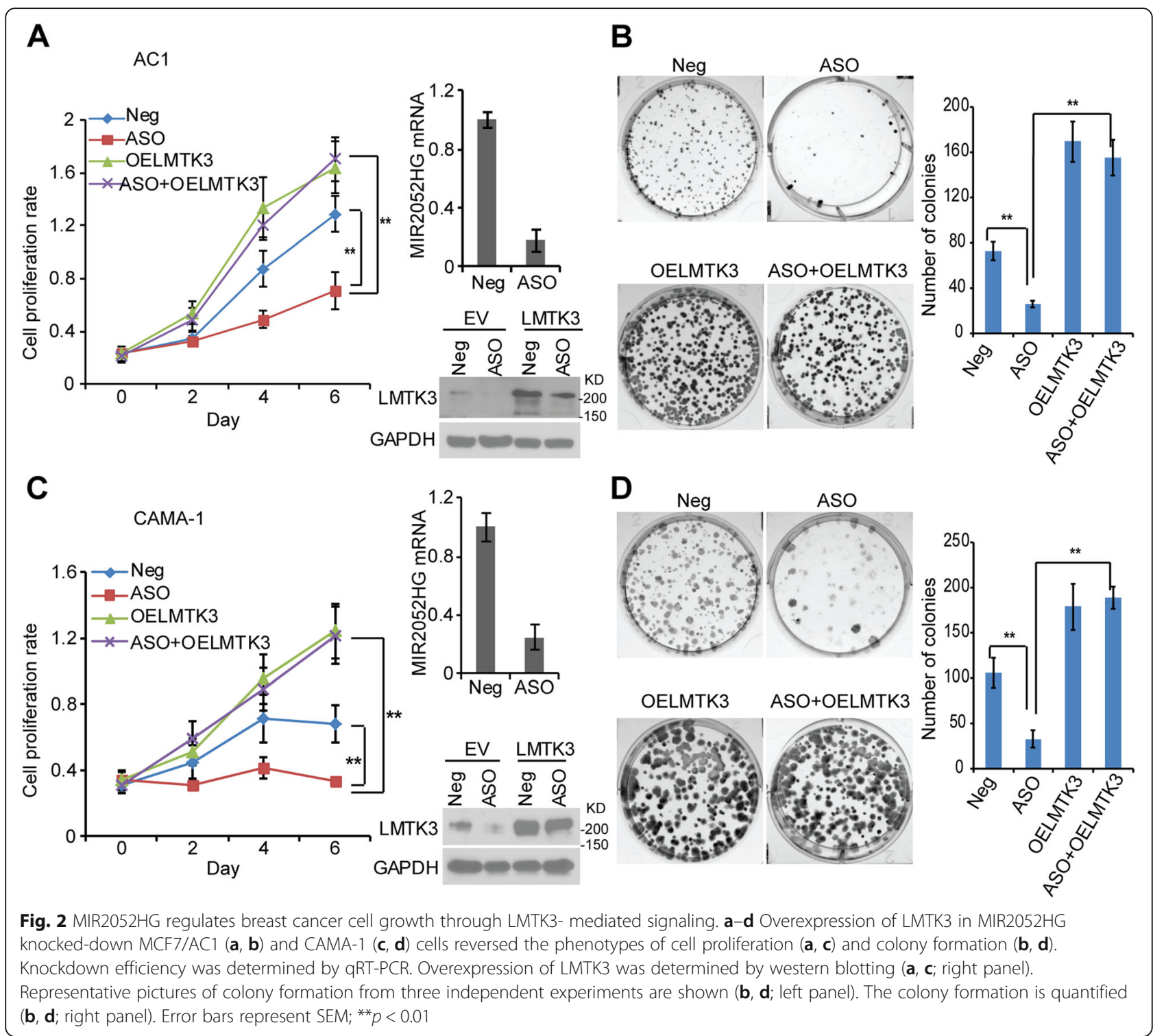

cells transfected with MIR2052HG ASO, coinciding with increased ER $\alpha$ pSer167, pMEK, pERK, and pRSK1 levels were also increased, indicating an increased MEK/ ERK/p90RSK1 activity. We then examined the role of LMTK3 in MIR2052HG-mediated regulation of MEK/ERK/p90RSK1 activity and found that LMTK3 overexpression abolished increased pMEK/pERK/ p90RSK1 levels caused by MIR2052HG silencing, resulting in increased ER $\alpha$ protein (Fig. 4c, d) and its transcriptional activity (Additional file 3: Figure S1b). These data further imply that MIR2052HG regulates LMTK3 expression, which then influences MEK/ERK/p90RSK1 activity, regulating ER $\alpha$ protein levels.

As protein kinase $\mathrm{C}(\mathrm{PKC})$ has been implicated to play a role in ER $\alpha$ protein degradation [38] and AKT-
FOXO3 regulation [39], and LMTK3 inhibits PKC activity [24], we examined the effects of MIR2052HG and LMTK3 on PKC. Downregulation of MIR2052HG increased PKC activity (Fig. 4e, f, and Additional file 3: Figure S1c), whereas overexpression of LMTK3 decreased PKC activity (Fig. 4e, f, and Additional file 3: Figure S1c). In addition, LMTK3 overexpression dramatically reduced PKC activity that was induced by MIR2052HG silencing (Fig. 4e, f, and Additional file 3: Figure S1c). Inhibition of PKC with the Go 6983 inhibitor reduced MEK/ERK/p90RSK1 activity and ER $\alpha$ pSer167, which in turn, partially rescued ER $\alpha$ levels (Fig. 4g), suggesting that MIR2052HG regulated ER $\alpha$ protein level through the axis of LMTK3/PKC/MEK/ ERK/RSK1. Our findings also confirmed that MIR2052HG effects on AKT/FOXO3 activation and 


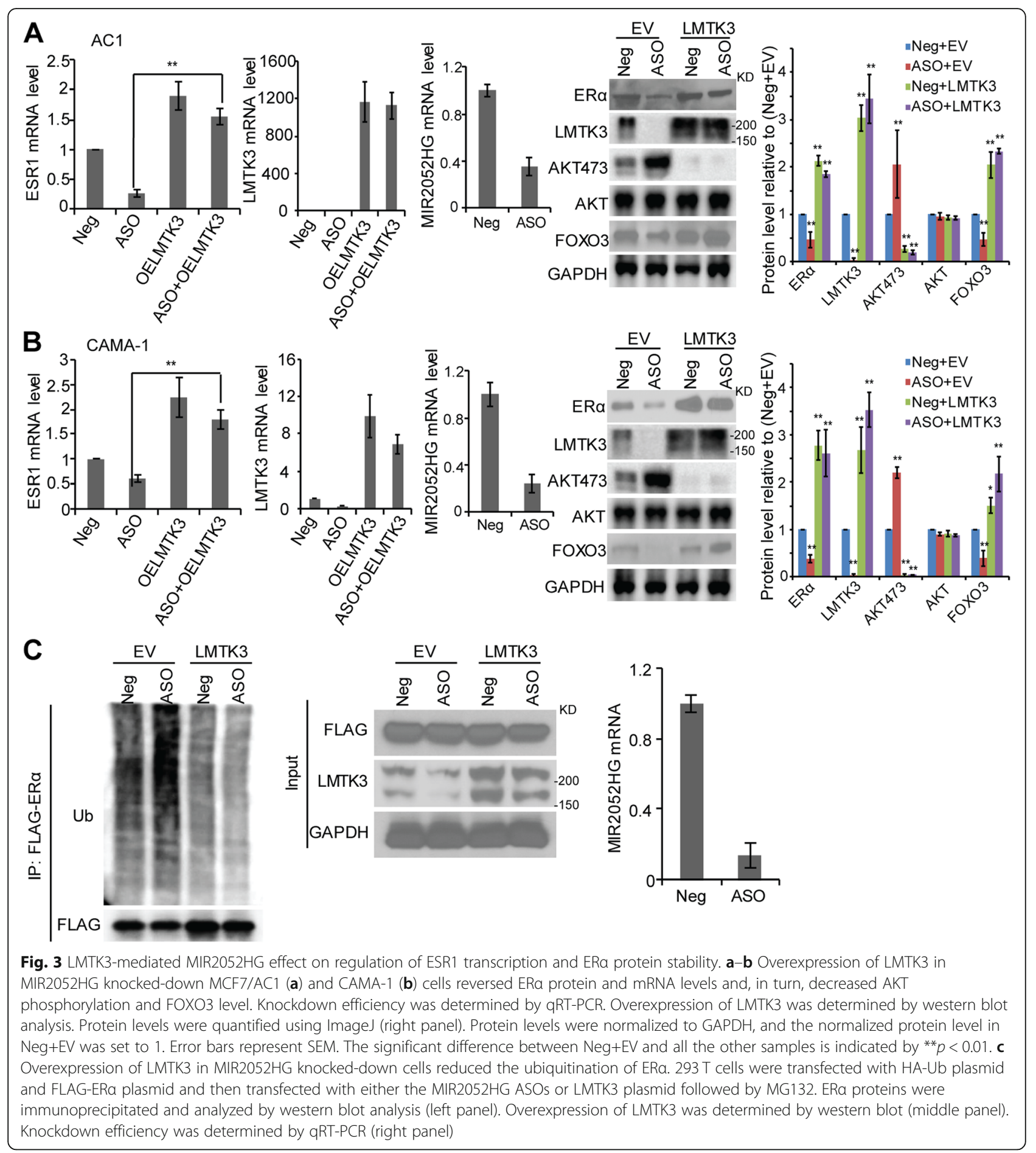

downstream ESR1 mRNA level were through the regulation of LMTK3/PKC pathway (Figs. 3 and 4).

\section{MIR2052HG contributes to LMTK3 transcription by} facilitating EGR1 recruitment

Next, we wanted to address how MIR2052HG regulates LMTK3 transcription. First, we examined the localization of the MIR2052HG RNA transcript. RNA-FISH demonstrated that MIR2052HG localized to a limited number of nuclear foci (one to two spots in most cases), suggesting that MIR2052HG had limited targets. We also checked the genomic location of the MIR2052HG transcript by RNA-DNA dual FISH, and the results showed that the MIR2052HG transcript was located at the LMTK3 gene 

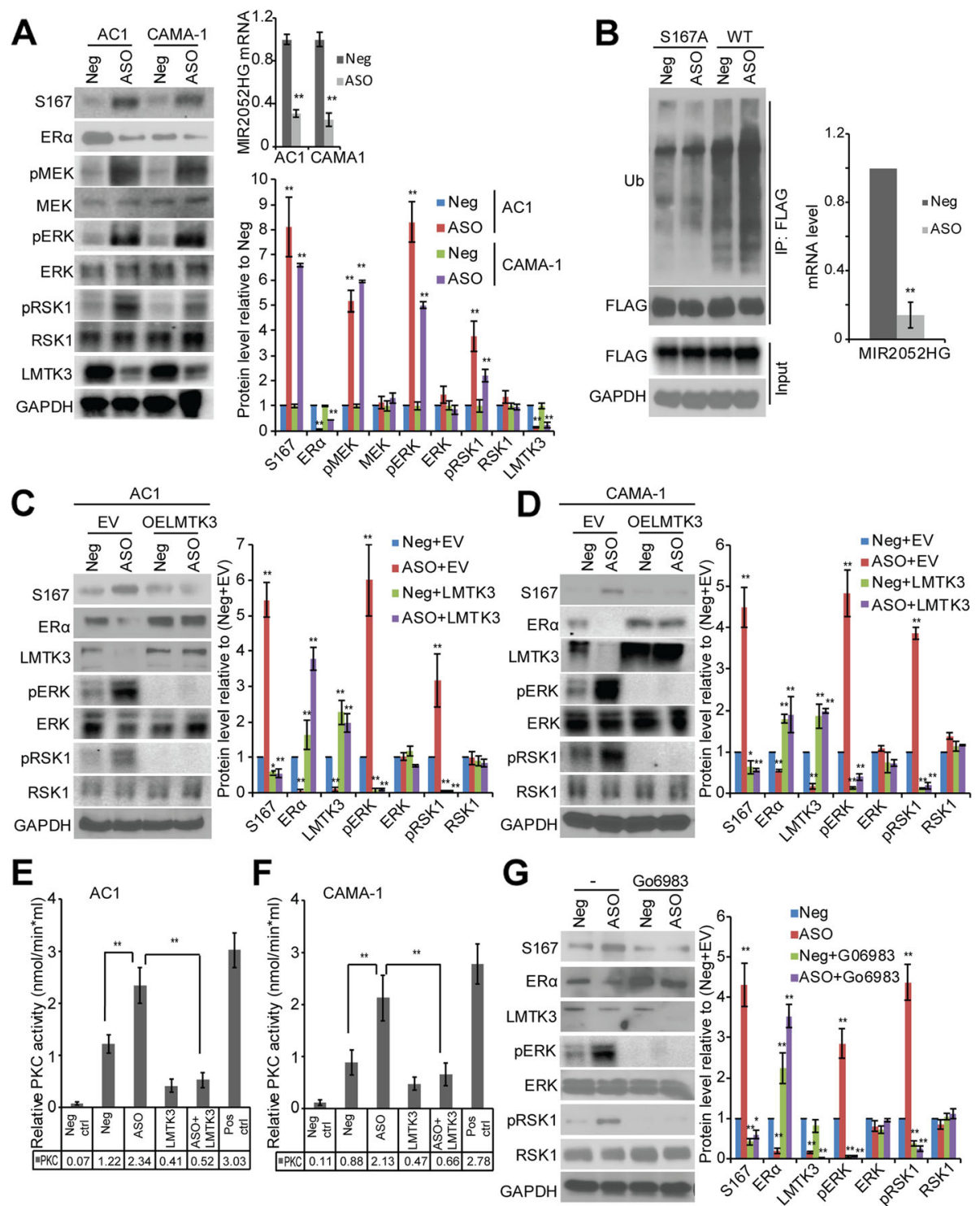

Fig. 4 MIR2052HG regulates ERa protein stability through MEK/ERK/RSK1 pathway. a Knockdown of MIR2052HG increased phosphorylation of MEK, ERK, RSK1, as well as ERa S167 and decreased LMTK3 total level in MCF7/AC1 and CAMA-1 cells. Protein levels were quantified as described in Fig. 3. Error bars represent SEM. The significant difference between Neg and ASO is indicated by $*^{*} p<0.01$. b Knockdown of MIR2052HG promoted the ubiquitination of wild-type ERa, but not ERa S167A mutant. 293 T cells were transfected with HA-Ub plasmid and FLAG-ERa or FLAG-ERa S167A plasmid and then transfected with either the MIR2052HG specific ASOs or the negative control ASO followed by MG132. Wildtype or S167A mutant ERa proteins were immunoprecipitated and analyzed by western blot. Knockdown efficiency in 293 T cells was determined by qRT-PCR. c-d Overexpression of LMTK3 in MIR2052HG knocked-down MCF7/AC1 (c) and CAMA-1 (d) cells reversed ERa protein levels and the phosphorylation of MEK, ERK, RSK1, and ERa S167. Overexpression of LMTK3 was determined by western blot analysis. Protein levels were quantified as described above. Error bars represent SEM. The significant difference between Neg+EV and all the other samples is indicated by: ${ }^{*} p$ $<0.05,{ }^{* *} p<0.01$. e-f PKC kinase assays examining the effect of MIR2052HG and LMTK3 on the catalytic activity of PKC in MCF7/AC1 (e) and CAMA-1 (f) cells. Error bars represent SEM of two independent experiments in triplicate; ${ }^{* *} p<0.01$. g Effects of MIR2052HG silencing on ERa protein levels in the presence of a PKC inhibitor (Go 6983). Protein levels were quantified as described above. Error bars represent SEM. The significant difference between Neg and all the other samples is indicated by ${ }^{*} p<0.05,{ }^{* *} p<0.01$

locus (Fig. 5a, Additional file 4: Figure S2). Taken together, these data suggest that MIR2052HG is likely involved in LMTK3 transcription.

LMTK3 expression could be activated by several transcription factors based on the ENCODE database, including BHLHE40, CHD2, CTCF, EGR1, EP300, EZH2, HDAC6, POLR2A, REST, CREBBP, YY1, and STAT1. Therefore, we asked whether any of these transcription factors, together with MIR2052HG might be involved in the regulation of MIR2052HG expression. 


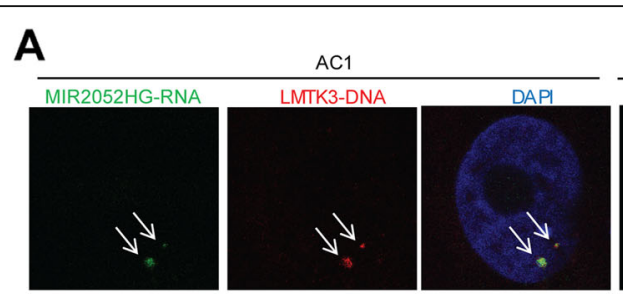

B $\quad$ AC1

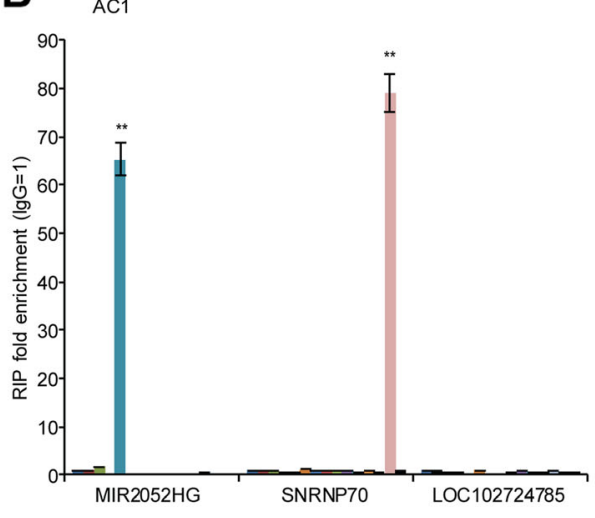

C

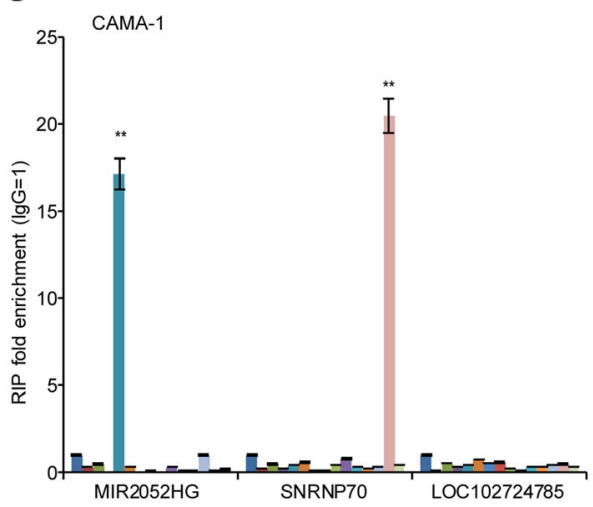

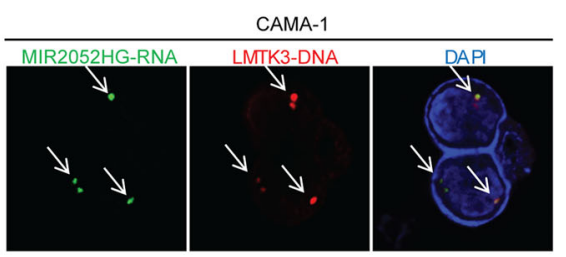

$=\lg G$

-BHLHE40

-CHD2

๓CTCF

चGR1

EP300

-EZH2

-HDAC6

-POLR2A

घEST

-CREBPB

ॠYY1

STAT1

SNRNP70
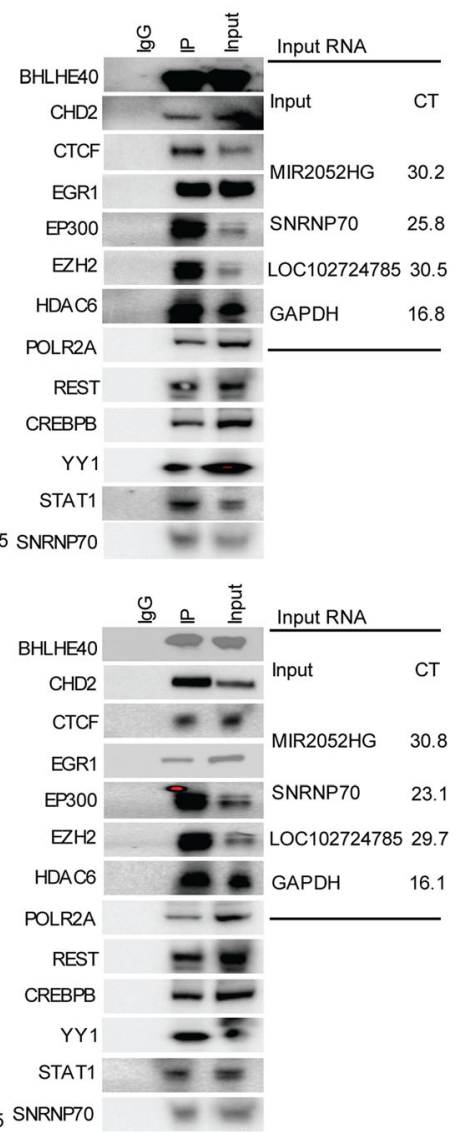

Fig. 5 MIR2052HG regulates LMTK3 transcription by facilitating EGR1 recruitment to the LMTK3 promoter. a Dual RNA-DNA-FISH demonstrates that MIR2052HG transcripts (green signal) are localized onto the LMTK3 gene locus (red signal) in MCF7/AC1 and CAMA-1 cells. b, $\mathbf{c}$ EGR1 antibody immunoprecipitates MIR2052HG, but not negative control IncRNA LOC102724785 in MCF7/AC1 (b) and CAMA-1 (c) cells. Error bars represent SEM of two independent experiments in triplicate; ${ }^{* *} p<0.01$

Immunoprecipitation followed by qRT-PCR analysis demonstrated that MIR2052HG was significantly enriched in the EGR1 immunoprecipitates (Fig. 5b, c). The enrichment of MIR2052HG by the EGR1 antibody was specific, as the antibody did not pull down another lncRNA, LOC102724785 (Fig. 5b, c). Knockdown of MIR2052HG did not change LMTK3 expression in a HER2-positive Au565 and a TNBC MDA-MB-231 cell lines, and no significant enrichment of MIR2052HG by the EGR1 antibody was observed in AU565 and MDA-MB-231 cells (Additional file 5: Figure S3). These data suggest that MIR2052HG regulation of LMTK3 transcription involves EGR1 in ER-positive breast cancer.
EGR1 was highly expressed in The Cancer Genome Atlas (TCGA) [40] ER-positive breast cancer patients (Additional file 6: Figure S4). We then confirmed EGR1 regulation of LMTK3 gene expression in the MCF7/AC1 and CAMA-1 cells. Knockdown of EGR1 reduced LMTK3 mRNA level (Fig. 6a, b). To examine whether binding of EGR1 to the LMTK3 promoter requires MIR2052HG, we first mapped the binding locations of EGR1 on the LMTK3 gene locus (Fig. 6c, chr19:48994366-48994811, chr19:48996320-48996559, chr19:49015095-49015334). ChIP assays demonstrated that EGR1 bound to all three binding sites (Fig. 6d, e). Importantly, knocking down MIR2052HG reduced the EGR1 binding to the LMTK3 gene locus (Fig. 6d, e) without significant 

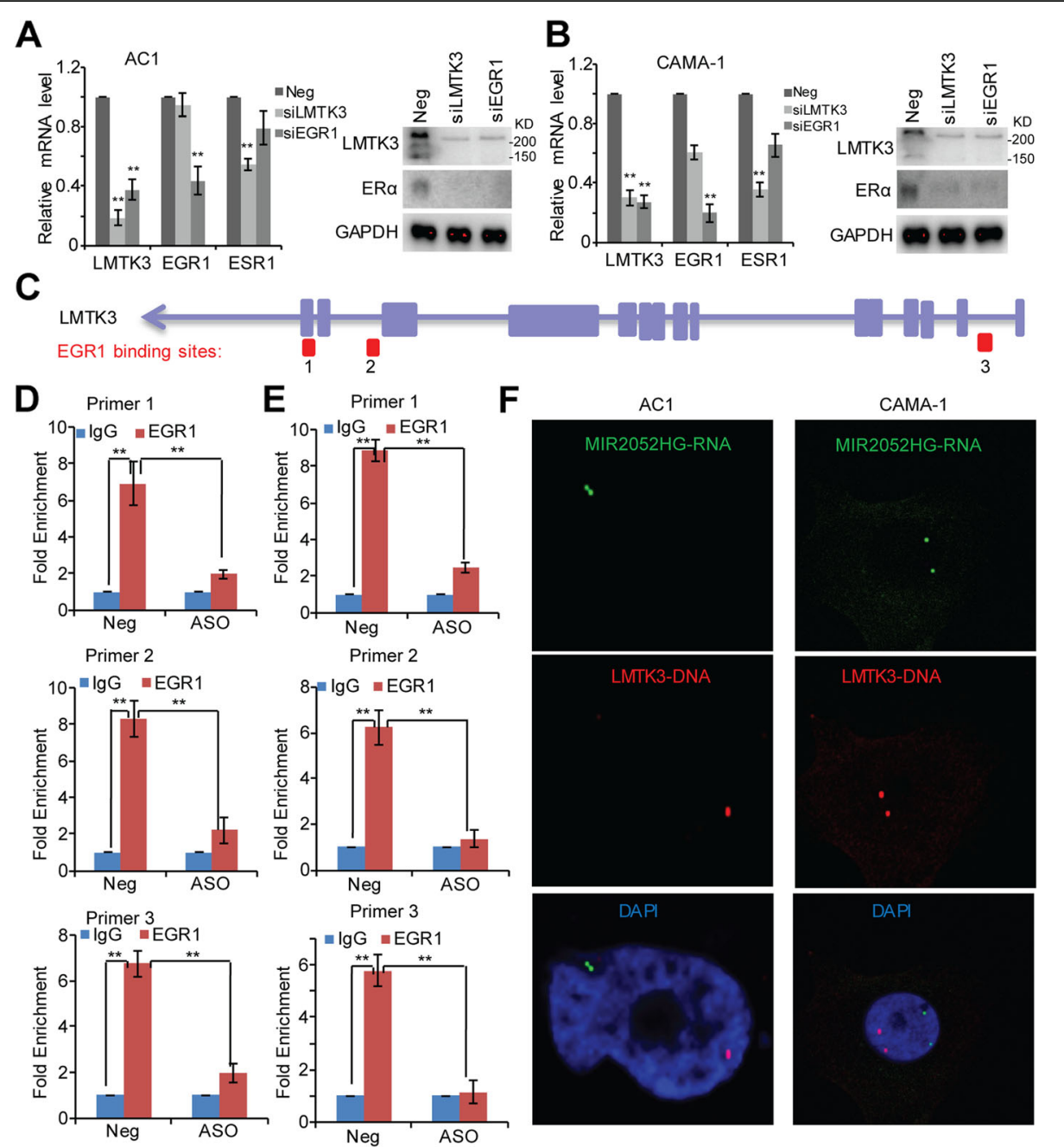

Fig. 6 MIR2052HG regulates LMTK3 transcription by regulating EGR1 binding to its motif in LMTK3 gene. a, b EGR1 regulates LMTK3 expression in MCF7/AC1 (a) and CAMA-1 (b) cells. $\mathbf{c}$ The EGR1 binding sites at the genomic location of the LMTK3 gene locus are indicated in the diagram. $\mathbf{d}, \mathbf{e}$ ChIP analysis demonstrates binding of EGR1 to LMTK3 gene locus in MCF7/AC1 (d) and CAMA-1 (e) cells. IgG serves as a control. Error bars represent SEM of two independent experiments in triplicate; ${ }^{* *} p<0.01$. $\mathbf{f}$ Dual RNA-DNA-FISH demonstrates that MIR2052HG transcripts (green signal) fail to localize to the LMTK3 gene locus (red signal) in EGR1 knockdown MCF7/AC1 and CAMA-1 cells

effect on the binding of EGR1 to other EGR1 targets (Additional file 7: Figure S5 and Additional file 8: Figure S6). Furthermore, MIR2052HG failed to locate in the LMTK3 gene locus in EGR1 knockdown cells (Fig. 6f). Although EGR1 remained as a transcription factor for LMTK3 in HER2-positive and TNBC cells and knockdown LMTK3 inhibited cell growth (Additional file 9: Figure S7), knocking down MIR2052HG did not change the EGR1 binding to LMTK3 gene locus (Additional file 9: Figure S7 c, d).

\section{Als modulate LMTK3 expression in a MIR2052HG SNP- dependent manner}

Our previous GWAS showed that MIR2025HG SNPs regulate its own gene expression as well as ER $\alpha$ expression in an estrogen or AI-dependent fashion [28]. Based on our findings showing MIR2025HG regulation of LMTK3, we then determined whether the expression of LMTK3 might be also SNP- and AI-dependent using the human LCLs system. This cell line model system, consisting of 300 individual LCLs for which we have extensive genomic and transcriptomic data, has shown repetitively to make it possible for us to study the relationship between common genetic variant and cellular phenotypes [28, 41, 42]. In the presence of androstenedione, LCLs with variant genotypes for both of the MIR2052HG SNPs, rs4476990 and rs3802201, showed dose-dependent increases in LMTK3 expression (Fig. 7a, b). However, addition of AI, either anastrozole (Fig. 7a) or exemestane (Fig. 7b) caused a "reversal" of the expression pattern with increased LMTK3 expression in LCLs with homozygous WT, but a marked decrease in 

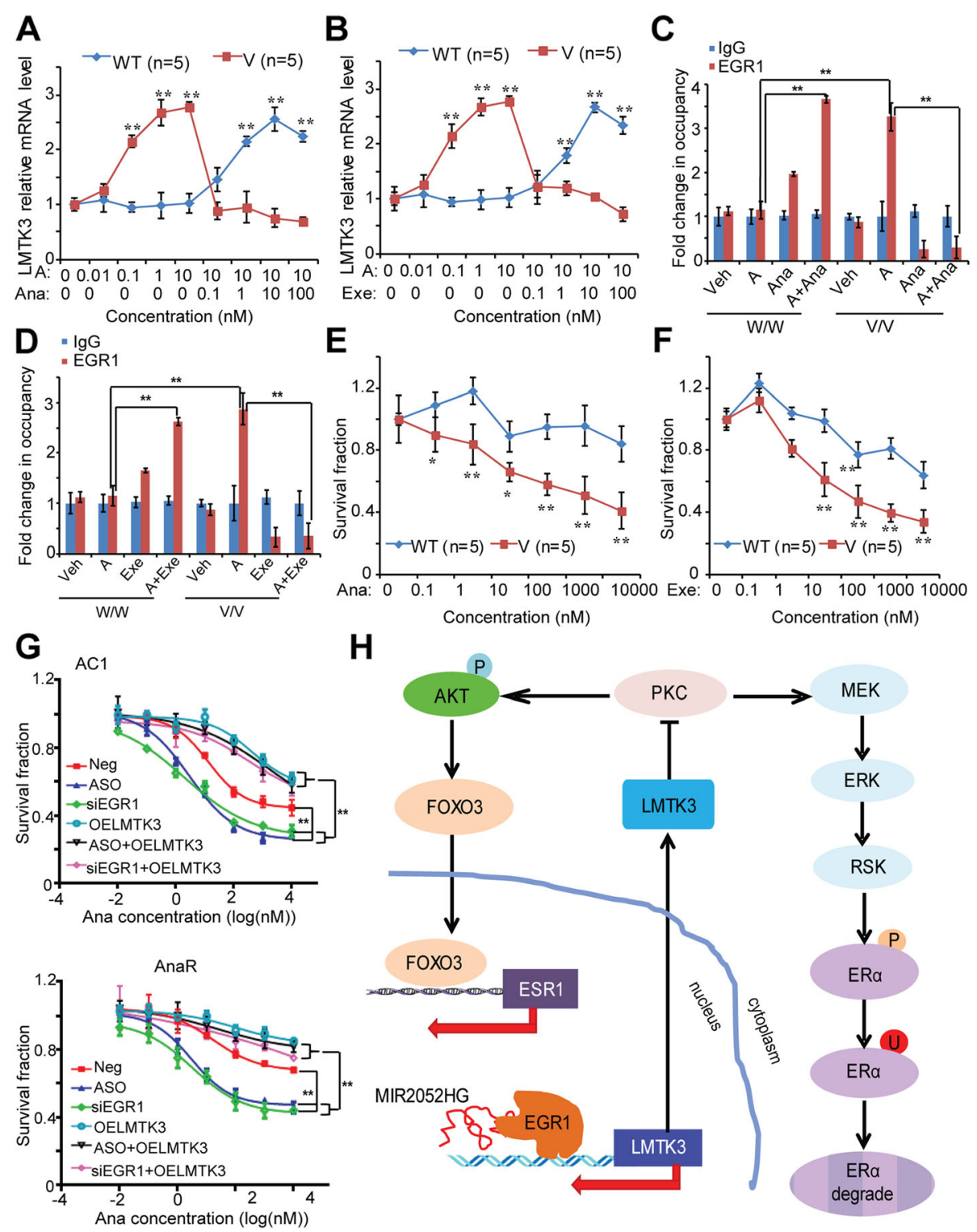

Fig. 7 MIR2052HG-mediated SNP-dependent LMTK3 expression. a, b Androstenedione induction of MIR2052HG expression is associated with the expression of LMTK3. Five LCLs with either MIR2052HG WT or variant SNPs were exposed to treatments. LMTK3 expression levels were analyzed in each LCL and the averaged expression levels were shown for WT $(n=5)$ or $\mathrm{V}(n=5) \mathrm{LCLs}$ after exposure to androstenedione alone or with increasing concentrations of anastrozole (a) or exemestane (b). Error bars represent SEM. ${ }^{* *} p<0.01$. The concentrations for androstenedione (A), anastrozole (Ana), and exemestane (Exe) are indicated. $\mathbf{c}, \mathbf{d}$ MIR2052HG SNPs determine androstenedione-dependent EGR1 binding to LMTK3 gene locus. ChIP assay using pooled LCLs $(n=5)$ with known genotypes for MIR2052HG SNPs demonstrates binding of EGR1 to LMTK3 gene locus after exposure to androstenedione alone or with anastrozole (c) or exemestane (d). Error bars represent SEM; ${ }^{* *} p<0.01$. e, $\mathbf{f}$ MIR2052HG SNP-dependent effect on Als response. LCLs were treated with increasing dose of anastrozole $(\mathbf{e})$ or exemestane $(\mathbf{f})$ in the presence of $10 \mathrm{nM}$ of androstenedione. Cell survival was analyzed $72 \mathrm{~h}$ after treatment for each $\mathrm{LCL}$, and the averaged survival was shown for $\mathrm{WT}(n=5)$ or $\mathrm{V}(n=5)$ LCLs. Error bars represent SEM. ${ }^{*} p<0.05,{ }^{*} p<0.01$. g Effects of MIR2052HG-EGR1-LMTK3 on anastrozole response. Dose response of anastrozole in MCF7/AC1 and MCF7/AnaR cells. Cells were transfected with ASO or siEGR1, with or without overexpression of LMTK3 for $24 \mathrm{~h}$, and then treated with anastrozole for $72 \mathrm{~h}$. Error bars represent SEM. ${ }^{* *} p<0.01$. $\mathbf{h}$ Hypothetical model illustrated how MIR2052HG might regulate LMTK3 transcription. The red arrows indicate the transcription direction. The transcribed MIR2052HG interacts with EGR1 protein and brings EGR1 to the LMTK3 locus. Together with other transcription machinery, binding of EGR1 to the LMTK3 promoter initiates transcription. LMTK3 protein inhibits the PKC, therefore downstream MAPK and AKT/FOXO3 pathways, leading to regulation of ERa degradation and ESR1 transcription 
LCLs homozygous for the variant genotypes. Of particular interest was the observation of a direct correlation between this pattern of expression for MIR2052HG and ER $\alpha$ [28] and that of LMTK3 (Fig. 7a, b). Since MIR2052HG regulated LMTK3 expression in a SNPand AI-dependent fashion (Fig. 7a, b), we determined if EGR1 binding to the LMTK3 promoter region was also SNP- and AI-dependent. In the presence of androstenedione, cells homozygous for the variant SNP genotypes showed increased binding of EGR1 to the LMTK3 promoter (Fig. 7c, d) relative to WT in ChIP assays using the EGR1 antibody. Anastrozole and exemestane could reverse this effect (Fig. 7c, d).

We next sought to determine the functional consequences of the MIR2025HG SNP on response to AIs. LCLs homozygous for the variant SNP, which have low LMTK3 expression (Fig. 7a, b), were more sensitive to anastrozole and exemestane than homozygous WT LCLs (Fig. 7e, f). To assess the role of MIR2052HG-EGR1-LMTK3 axis in AI response, we next used anastrozole-sensitive MCF7/AC1 (because of its high expression of the AI target, CYP19A1), and anastrozole-resistant MCF7/AnaR [43] cell lines to determine the role of MIR2052HG-EGR1-LMTK3 axis in these two settings. In both lines, knockdown of MIR2052HG or EGR1 significantly increased anastrozole sensitivity compared to negative control, whereas overexpression of LMTK3 in MIR2052HG-knockdown or EGR1-knockdown cells resulted in decreased AI sensitivity (Fig. 7g). These results suggest that MIR2052HG facilitates EGR1 recruitment to the LMTK3 promoter region in a SNP-dependent fashion to activate LMTK3 transcription, resulting in AI resistance.

\section{Discussions}

Resistance to endocrine therapy represents a major challenge for ER $\alpha$-positive breast cancer therapy. Therefore, the identification of biomarkers for endocrine response and understanding mechanisms of endocrine resistance should reveal possible strategies to overcome this problem. We have previously demonstrated that germline genetic variations in MIR2052HG were associated with breast cancer-free interval in the MA27 trial [28]. Downregulation of MIR2052HG reduced ER $\alpha$-positive breast cancer cell growth. The variant SNPs were associated with increased MIR2052HG expression due to increased ER $\alpha$ binding to EREs [28]. Therefore, MIR2052HG plays an important role in regulating ER $\alpha$ and endocrine resistance [28]. Recently, LMTK3, a serine-threonine-tyrosine kinase, has gained attention in breast cancer with respect to its roles in pathogenesis and therapy resistance of breast cancer $[24,44,45]$. Using the TCGA data set, LMTK3 showed higher expression level in ER-positive breast cancer patients compared with normal breast and triple negative subtype (Additional file 10: Figure S8a, $p=6.5 \mathrm{e}-09$ and $p$ $=3.0 \mathrm{e}-11$ respectively), and RNA expression levels were also independently associated with disease-free survival and overall survival (Additional file 10: Figure S8b). The fact that overexpression of LMTK3 significantly rescued the cell growth defect caused by MIR2052HG depletion suggests that LMTK3 is one of the downstream targets of MIR2052HG (Fig. 2). Furthermore, our data supported the notion that MIR2052HG tran-regulated LMTK3 transcription. MIR2052HG associated with EGR1 and facilitated its binding to the LMTK3 gene promoter to activate LMTK3 expression (Figs. 5 and 6), which in turn, promoted ER $\alpha$-positive breast cancer cell growth. As a direct target of MIR2052HG, LMTK3 regulated downstream PKC/AKT/FOXO3 and PKC/MAPK/RSK1/ER $\alpha$ signaling, therefore regulating ER $\alpha$-positive breast cancer growth and AI response (Figs. 2, 3, and 4). Although MIR2052HG did not regulate LMTK3 expression in ER $\alpha$-negative cells (Additional file 5: Figure S3), downregulation of LMTK3 inhibited ER $\alpha$-negative cell proliferation (Additional file 9: Figure S7A, B), indicating LMTK3 may regulate other downstream pathways.

LncRNAs can play diverse roles in regulating gene expression as well as other cellular activities in breast cancer [46-48]. LncRNAs produce their cellular effects via several distinct mechanisms, including acting both in cis and trans [29, 30]. Here, we demonstrated that MIR2052HG exerted its oncogenic role by regulating LMTK3 expression. LMTK3 is significantly elevated in high-grade breast tumors and is associated with poor survival rates in different breast cancer cohorts $[24,26]$. A prior study has shown that methylation is not a prevalent mechanism in the control of LMTK3 expression in breast cancer, and several somatic mutations in LMTK3 have been associated with overall survival [24]. However, we did not find any germline variations in LMTK3 associated with breast cancer recurrence in our MA.27 cohort, suggesting a LMTK3 upstream regulator such as MIR2052HG might be the driving factor influencing this clinical phenotype. We found that MIR2052HG was induced by hormone or AIs, and it was required for the LMTK3-mediated phenotypes, including cell growth in response to AIs (Fig. 7). Current research into the potential role of LMTK3 as a therapeutic target is underway $[49,50]$. At mechanistic level, we found that MIR2052HG positively regulated ER $\alpha$ at both mRNA and protein levels via LMTK3 to maintain the cancer cell growth. LMTK3 mediated the effect of MIR2052HG on AI response via ER $\alpha$ transcription through the LMTK3/PKC/AKT/FOXO3 signaling and protein levels via the LMTK3/PKC/MAPK pathway (Figs. 3 and 4). We also found a positive correlation between the expressions of LMTK3 and ESR1 (Additional file 10: Figure S8c and d) in the METABRIC and TCGA set data 
sample set [40], as well as in our LCLs model $(p=3.45 \mathrm{e}$ -04 , rho $=0.212$ ). Due to the low expression levels of MIR2052HG in some of the patient samples (Additional file 6: Figure S4), we did not find strong correlation between the expressions of MIR2052HG and LMTK3, and the correlations between MIR2052HG RNA expression levels and disease-free survival or overall survival in TCGA cBioPortal are not available.

EGR1 is an immediate-early gene induced by estrogen, growth factors, or stress signals [51]. The EGR1 protein binds to a specific $\mathrm{GC}$-rich sequence in the promoter region of many genes to regulate the expression of these target genes including growth factors and cytokines. The mechanisms by which EGR1 activates downstream target genes appears to be cell-context dependent [52-54]. Although the DNA-binding domain of EGR1 is capable of binding to DNA through the GC-rich consensus sequence GCG (G/T) GGGCG, EGR1 can act as either an activator or a repressor of transcription through mechanisms that depend on interactions with distinct cofactors, and thus many partners, including DNA-binding proteins, have been reported to form complexes with EGR1 to activate EGR1 target gene expression $[55,56]$. In our study, we demonstrated that the association of MIR2052HG with EGR1 facilitated EGR1 binding to the LMTK3 gene locus (Figs. 5 and 6). Based on the current data, we propose a hypothetical model that may explain how MIR2052HG contributes to LMTK3 activation and AI resistance (Fig. $7 \mathrm{~h}$ ). In the model, we showed that MIR2052HG facilitated the recruitment of EGR1 to the LMTK3 gene through its interaction with EGR1and activated LMTK3 transcription. This process might also involve other transcription cofactors. It is possible that other proteins are also required for the binding of MIR2052HG to EGR1, since some RNA-binding proteins have been shown to be able to regulate EGR1 [57]. Although our data showed that EGR1 binds to three binding sites in LMTK3 gene locus and MIR2052HG affects all three sites binding activity (Fig. 6d, e), this study did not address the difference in gene regulation among the three EGR1 binding sites. One potential explanation could be the existence of homotypic clusters, that is, many adjacent transcription factor binding sites for the same transcription factor. Homotypic clusters might influence gene regulation through cooperativity or no cooperativity mechanisms [58]. Future studies may also explore whether the three binding sites involve in transcribing different LMTK3 variants. Nevertheless, RNA-mediated EGR1 targeting represents one mechanism by which EGR1 is recruited to its targets.

\section{Conclusions}

Our findings support a model in which the protective MIR2052HG variant genotype regulates LMTK3 expression by enhancing the recruitment of ERG1 to the LMTK3 promoter region, activating its transcription. At the mechanistic level, LMTK3 regulates ER $\alpha$ stability via the PKC/MEK/ERK/RSK1 axis and ER $\alpha$ transcription through $\mathrm{PKC} / \mathrm{AKT} / \mathrm{FOXO} 3$ pathway. This regulation may explain the effect of the MIR2052HG variant genotype on cell proliferation and response to AIs in MA.27. These findings provide new insight into the mechanism of action of MIR2052HG and suggest that LMTK3 may be a new therapeutic target in ER $\alpha$-positive breast cancer patients, especially those who might not respond to AIs.

\section{Additional files}

Additional file 1: Table S1. Primers for LMTK3 CHIP assay. (XLSX 9 kb) Additional file 2: Table S2. RNA-seq results after MIR2052HG and LMTK3 knockdown. Overlapped genes between knockdown MIR2052HG and knockdown LMTK3 are highlighted. Pathway analysis of common dysregulated genes in both MIR2052HG and knockdown LMTK3 knockdowns. (XLSX $1523 \mathrm{~kb}$ )

Additional file 3: Figure S1. LMTK3 mediates MIR2052HG- regulation of ERa. a Overexpression of LMTK3 in MIR2052HG knocked-down MCF7/ AC1 and CAMA-1 cells did not change AKT and FOXO3 mRNA levels. b Expression profiles of ER target genes in MCF7/AC1 and CAMA-1 cells. Cells were transfected with ASO and LMTK3 plasmid. RNA was prepared $24 \mathrm{~h}$ following transfection. c Effects of MIR2052HG and LMTK3 on the ability of PKC to phosphorylate its substrates. (TIF 1963 kb)

Additional file 4: Figure S2. LMTK3 DNA FISH probe map with two options for BACs that cover LMTK3 gene region which were $166 \mathrm{~kb}$ and $215 \mathrm{~kb}$. (TIF $3156 \mathrm{~kb}$ )

Additional file 5: Figure S3. Knockdown of MIR2052HG does not affect LMTK3 expression and proliferation of HER2+ and TNBC cells. $a-b$ Cell proliferation of HER+ Au565 (a) and TNBC MDA-MB-231 (b) cells after knocking down MIR2052HG. LMTK3 gene expression and MIR2052HG knockdown efficiency was determined by qRT-PCR. c-d EGR1 antibody failed to immunoprecipitate MIR2052HG in Au565 (c) and MDA-MB-231 (d) cells. Error bars represent SEM of two independent experiments in triplicate. (TIF $1019 \mathrm{~kb}$ )

Additional file 6: Figure S4. MIR2052HG and EGR1 expression in TCGA ER-positive breast cancer patients. (TIF $1311 \mathrm{~kb}$ )

Additional file 7: Figure S5. Knockdown of MIR2052HG specifically reduces binding of EGR1 to the LMTK3 promoter, but not the other EGR1 targets. a-b Relative mRNA expression of EGR1 targeted genes after knockdown of EGR1 in MCF7/AC1 (a) and CAMA-1 (b) cells. Error bars represent SEM; ${ }^{*} p<0.05,{ }^{* *} p<0.01$. c-d Relative mRNA expression of EGR1 targeted genes after knockdown of MIR2052HG in MCF7/AC1 (c) and CAMA-1 (d) cells. Error bars represent SEM; ${ }^{*} p<0.05$, Non-significant (NS): $p>0.05$. (TIF $1454 \mathrm{~kb}$ )

Additional file 8: Figure S6. MIR2052HG has no significant effect on other EGR1 targeted genes. a EGR1 reporter assay in MIR2052HG knocked-down MCF7/AC1 and CAMA1 cells. b ChIP analysis demonstrates binding of EGR1 to additional EGR1 targeted genes and knockdown of MIR2052HG has no impact on the binding. IgG serves as a control. Error bars represent SEM; Non-significant (NS): $p>0.05$. (TIF $848 \mathrm{~kb}$ )

Additional file 9: Figure S7. EGR1, but not MIR2052HG, regulates LMTK3 expression in HER2+ and TNBC cells. $a-b$ Cell proliferation of HER + Au565 (a) and TNBC MDA-MB-231 (b) cells after knocking down LMTK3. LMTK3 gene expression and EGR1 knockdown efficiency was determined by qRT-PCR. $c-d$ ChIP analysis demonstrates the binding of EGR1 to the promoter region of the LMTK3 gene locus in AU565 (c) and MDA-MB-231 (d) cells. However, knockdown of MIR2052HG did not change the binding. IgG serves as a control. Error bars represent SEM of three 
independent experiments in triplicate: ${ }^{* *} p<0.01$, Non-significant (NS): $p>0.05$. (TIF $1117 \mathrm{~kb})$

Additional file 10: Figure S8. Correlations of LMTK3 expression with ESR1. a LMTK3 expression in TCGA breast cancer patients. There are significant differences in the mean expression of LMTK3 among the four groups (HER2, ER+, TN, and Normal) using Kruskal-Wallis test $(p<2.2 \mathrm{e}$ -16). Pairwise comparison Wilcoxon test was also performed to determine the LMTK3 expression difference between the subtypes. Using Bonferroni correction for multiple testing, pairwise comparison showed: LMTK3 level in TN subtype is different from HER2 $(p=2.4 \mathrm{e}-08)$ and ER+ $(p=3.0 \mathrm{e}-11)$ but not significantly different from Normal $(p=0.17)$; LMTK3 in HER2 subtype is different from Normal $(p=1.5 \mathrm{e}-07)$ but not from ER positive ( $p=0.892)$; while ER+ is significantly different from Normal ( $p=$ 6.5e-09). b Kaplan-Meier plots demonstrated the associations between LMTK3 expression level and overall survival $(p=3.927 \mathrm{e}-5)$ as well as disease-free survival $(p=9.587$ e-5) in TCGA ER-positive breast cancer patients. c Correlations of LMTK3 expression with ESR1 in 2509 METABRIC breast cancer patients. d Correlations of LMTK3 expression with ESR1 in TCGA breast cancer patients. (TIF $2271 \mathrm{~kb}$ )

\section{Abbreviations}

Al: Aromatase inhibitor; ASO: Antisense oligonucleotides; ChIP: Chromatin immunoprecipitation; EGR1: Early growth response protein 1; ERE: Estrogen response element; ERa: Estrogen receptor a; FISH: Fluorescent in situ hybridization; GWAS: Genome-wide association study; LCL: Lymphoblastoid cell line; LMTK3: Lemur tyrosine kinase-3; LncRNA: Long noncoding RNA; PKC: Protein kinase C; qRT-PCR: Quantitative real-time PCR assay; RIP: RNAbinding protein immunoprecipitation; SNP: Single-nucleotide polymorphisms; TCGA: The Cancer Genome Atlas; WT: Wild type

\section{Acknowledgements}

The authors acknowledge the women who participated in the MA.27 clinical trial and provided DNA and consent for its use in genetic studies. This research was supported by the Breast Cancer Research Foundation (BCRF), R01CA196648, UG1CA18967, P50CA116201 (Mayo Clinic Breast Cancer Specialized Program of Research Excellence), U1961388 (the Pharmacogenomics Research Network), the George M. Eisenberg Foundation for Charities, and the Nan Sawyer Breast Cancer Fund.

\section{Funding}

This work was supported by the Breast Cancer Research Foundation [BCRF18-076]; National Cancer Institute [UG1CA18967]; Mayo Clinic Breast Cancer Specialized Program of Research Excellence [P50CA116201]; the Pharmacogenomics Research Network [U1961388]; the George M. Eisenberg Foundation for Charities; and the Nan Sawyer Breast Cancer Fund.

\section{Availability of data and materials}

Data used in this study are included in this published article and its supplementary files.

\section{Authors' contributions}

JC, JNI, and LW designed the experiments. JC performed the experiments and data analysis. KRK did the data analysis. MK, LES, and JNI conducted the MA.27 study. JC, JNI, LW, MPG, and RMW interpreted the results and COwrote the manuscript. All authors read and approved the final manuscript.

\section{Ethics approval and consent to participate}

Not applicable.

\section{Consent for publication}

Not applicable.

\section{Competing interests}

Drs. Wang and Weinshilboum are co-founders of OneOme. No direct conflict of interest with this work. The authors declare that they have no conflict of interests.

\section{Publisher's Note}

Springer Nature remains neutral with regard to jurisdictional claims in published maps and institutional affiliations.

\section{Author details}

${ }^{1}$ Department of Molecular Pharmacology and Experimental Therapeutics, Mayo Clinic, Rochester, MN 55905, USA. ²Division of Medical Oncology, Mayo Clinic, Rochester, MN 55905, USA. ${ }^{3}$ Department of Health Sciences Research, Mayo Clinic, Rochester, MN 55905, USA. ${ }^{4} \mathrm{NCIC}$ Clinical Trials Group, Kingston, Ontario K7L 3N6, Canada. ${ }^{5}$ RIKEN Center for Integrative Medical Science, Yokohama City 230-0045, Japan.

Received: 11 January 2019 Accepted: 25 March 2019

Published online: 03 April 2019

\section{References}

1. Allred DC, Harvey JM, Berardo M, Clark GM. Prognostic and predictive factors in breast cancer by immunohistochemical analysis. Mod Pathol. 1998;11(2):155-68.

2. Miller KD, Siegel RL, Lin CC, Mariotto $A B$, Kramer JL, Rowland JH, Stein KD, Alteri R, Jemal A. Cancer treatment and survivorship statistics, 2016. CA Cancer J Clin. 2016;66(4):271-89.

3. Goss PE, Strasser K. Aromatase inhibitors in the treatment and prevention of breast cancer. J Clin Oncol. 2001;19(3):881-94.

4. Miller WR. Aromatase inhibitors: mechanism of action and role in the treatment of breast cancer. Semin Oncol. 2003;30(4 Suppl 14):3-11.

5. Ali $\mathrm{S}, \mathrm{Coombes} \mathrm{RC}$. Endocrine-responsive breast cancer and strategies for combating resistance. Nat Rev Cancer. 2002;2(2):101-12.

6. Clarke R, Liu MC, Bouker KB, Gu Z, Lee RY, Zhu Y, Skaar TC, Gomez B, O'Brien $K$, Wang $Y$, et al. Antiestrogen resistance in breast cancer and the role of estrogen receptor signaling. Oncogene. 2003;22(47):7316-39.

7. Brueggemeier RW. Aromatase, aromatase inhibitors, and breast cancer. Am J Ther. 2001;8(5):333-44.

8. Kuske B, Naughton C, Moore K, Macleod KG, Miller WR, Clarke R, Langdon $\mathrm{SP}$, Cameron DA. Endocrine therapy resistance can be associated with high estrogen receptor alpha (ERalpha) expression and reduced ERalpha phosphorylation in breast cancer models. Endocr Relat Cancer. 2006;13(4): 1121-33.

9. Chawla A, Repa JJ, Evans RM, Mangelsdorf DJ. Nuclear receptors and lipid physiology: opening the X-files. Science. 2001;294(5548):1866-70.

10. Bjornstrom L, Sjoberg M. Mechanisms of estrogen receptor signaling: convergence of genomic and nongenomic actions on target genes. Mol Endocrinol. 2005;19(4):833-42.

11. Katzenellenbogen BS, Kendra KL, Norman MJ, Berthois Y. Proliferation, hormonal responsiveness, and estrogen receptor content of MCF-7 human breast cancer cells grown in the short-term and long-term absence of estrogens. Cancer Res. 1987;47(16):4355-60.

12. Chan CM, Martin LA, Johnston SR, Ali S, Dowsett M. Molecular changes associated with the acquisition of oestrogen hypersensitivity in MCF-7 breast cancer cells on long-term oestrogen deprivation. J Steroid Biochem Mol Biol. 2002;81(4-5):333-41.

13. Martin LA, Farmer I, Johnston SR, Ali S, Dowsett M. Elevated ERK1/ERK2/ estrogen receptor cross-talk enhances estrogen-mediated signaling during long-term estrogen deprivation. Endocr Relat Cancer. 2005;12(Suppl 1):S75-84.

14. Santen RJ, Song RX, Zhang Z, Kumar R, Jeng MH, Masamura A, Lawrence J $\mathrm{Jr}$, Berstein L, Yue W. Long-term estradiol deprivation in breast cancer cells up-regulates growth factor signaling and enhances estrogen sensitivity. Endocr Relat Cancer. 2005;12(Suppl 1):S61-73.

15. Ali S, Metzger D, Bornert JM, Chambon P. Modulation of transcriptional activation by ligand-dependent phosphorylation of the human oestrogen receptor A/B region. EMBO J. 1993;12(3):1153-60.

16. Robinson DR, Wu YM, Vats P, Su F, Lonigro RJ, Cao X, Kalyana-Sundaram S, Wang $R$, Ning $Y$, Hodges $L$, et al. Activating ESR1 mutations in hormoneresistant metastatic breast cancer. Nat Genet. 2013;45(12):1446-51.

17. Kato S, Endoh H, Masuhiro Y, Kitamoto T, Uchiyama S, Sasaki H, Masushige S, Gotoh Y, Nishida E, Kawashima H, et al. Activation of the estrogen receptor through phosphorylation by mitogen-activated protein kinase. Science. 1995;270(5241):1491-4.

18. Arnold SF, Obourn JD, Jaffe H, Notides AC. Serine 167 is the major estradiolinduced phosphorylation site on the human estrogen receptor. Mol Endocrinol. 1994;8(9):1208-14. 
19. Chen D, Washbrook E, Sarwar N, Bates GJ, Pace PE, Thirunuvakkarasu V, Taylor J, Epstein RJ, Fuller-Pace FV, Egly JM, et al. Phosphorylation of human estrogen receptor alpha at serine 118 by two distinct signal transduction pathways revealed by phosphorylation-specific antisera. Oncogene. 2002; 21(32):4921-31.

20. Weitsman GE, Li L, Skliris GP, Davie JR, Ung K, Niu Y, Curtis-Snell L, Tomes L, Watson PH, Murphy LC. Estrogen receptor-alpha phosphorylated at Ser118 is present at the promoters of estrogen-regulated genes and is not altered due to HER-2 overexpression. Cancer Res. 2006;66(20):10162-70.

21. Bunone G, Briand PA, Miksicek RJ, Picard D. Activation of the unliganded estrogen receptor by EGF involves the MAP kinase pathway and direct phosphorylation. EMBO J. 1996;15(9):2174-83.

22. Joel PB, Smith J, Sturgill TW, Fisher TL, Blenis J, Lannigan DA. pp90rsk1 regulates estrogen receptor-mediated transcription through phosphorylation of Ser-167. Mol Cell Biol. 1998;18(4):1978-84.

23. Clark DE, Poteet-Smith CE, Smith JA, Lannigan DA. Rsk2 allosterically activates estrogen receptor alpha by docking to the hormone-binding domain. EMBO J. 2001;20(13):3484-94.

24. Giamas G, Filipovic A, Jacob J, Messier W, Zhang H, Yang D, Zhang W, Shifa BA, Photiou A, Tralau-Stewart C, et al. Kinome screening for regulators of the estrogen receptor identifies LMTK3 as a new therapeutic target in breast cancer. Nat Med. 2011;17(6):715-9.

25. Park S, Song J, Joe CO, Shin I. Akt stabilizes estrogen receptor alpha with the concomitant reduction in its transcriptional activity. Cell Signal. 2008; 20(7):1368-74

26. Stebbing J, Filipovic A, Lit LC, Blighe K, Grothey A, Xu Y, Miki Y, Chow LW, Coombes RC, Sasano $H$, et al. LMTK3 is implicated in endocrine resistance via multiple signaling pathways. Oncogene. 2013;32(28):3371-80.

27. Jiang J, Sarwar N, Peston D, Kulinskaya E, Shousha S, Coombes RC, Ali S. Phosphorylation of estrogen receptor-alpha at Ser167 is indicative of longer disease-free and overall survival in breast cancer patients. Clin Cancer Res. 2007;13(19):5769-76.

28. Ingle JN, Xie F, Ellis MJ, Goss PE, Shepherd LE, Chapman JW, Chen BE, Kubo M, Furukawa Y, Momozawa Y, et al. Genetic polymorphisms in the long noncoding RNA MIR2052HG offer a pharmacogenomic basis for the response of breast cancer patients to aromatase inhibitor therapy. Cancer Res. 2016;76(23):7012-23.

29. Rinn JL, Chang HY. Genome regulation by long noncoding RNAs. Annu Rev Biochem. 2012;81:145-66.

30. Ulitsky I, Bartel DP. lincRNAs: genomics, evolution, and mechanisms. Cell. 2013;154(1):26-46.

31. Wang KC, Chang HY. Molecular mechanisms of long noncoding RNAs. Mol Cell. 2011;43(6):904-14

32. Wu C, Luo J. Long non-coding RNA (IncRNA) Urothelial CarcinomaAssociated 1 (UCA1) enhances tamoxifen resistance in breast cancer cells via inhibiting mTOR signaling pathway. Med Sci Monit. 2016;22:3860-7.

33. Xue X, Yang YA, Zhang A, Fong KW, Kim J, Song B, Li S, Zhao JC, Yu J. LnCRNA HOTAIR enhances ER signaling and confers tamoxifen resistance in breast cancer. Oncogene. 2016;35(21):2746-55.

34. Namekawa SH, Lee JT. Detection of nascent RNA, single-copy DNA and protein localization by immunoFISH in mouse germ cells and preimplantation embryos. Nat Protoc. 2011;6(3):270-84.

35. Takizawa T, Gudla PR, Guo L, Lockett S, Misteli T. Allele-specific nuclear positioning of the monoallelically expressed astrocyte marker GFAP. Genes Dev. 2008;22(4):489-98.

36. Macedo LF, Guo Z, Tilghman SL, Sabnis GJ, Qiu Y, Brodie A. Role of androgens on MCF-7 breast cancer cell growth and on the inhibitory effect of letrozole. Cancer Res. 2006;66(15):7775-82.

37. Fernando RI, Wimalasena J. Estradiol abrogates apoptosis in breast cancer cells through inactivation of BAD: Ras-dependent nongenomic pathways requiring signaling through ERK and Akt. Mol Biol Cell. 2004;15(7):3266-84.

38. Marsaud V, Gougelet A, Maillard S, Renoir JM. Various phosphorylation pathways, depending on agonist and antagonist binding to endogenous estrogen receptor alpha (ERalpha), differentially affect ERalpha extractability, proteasome-mediated stability, and transcriptional activity in human breast cancer cells. Mol Endocrinol. 2003;17(10):2013-27.

39. Belguise K, Sonenshein GE. PKCtheta promotes c-Rel-driven mammary tumorigenesis in mice and humans by repressing estrogen receptor alpha synthesis. J Clin Invest. 2007;117(12):4009-21.

40. Cancer Genome Atlas N. Comprehensive molecular portraits of human breast tumours. Nature. 2012;490(7418):61-70.
41. Cairns J, Ingle JN, Wickerham LD, Weinshilboum R, Liu M, Wang L. SNPS near the cysteine proteinase cathepsin O gene (CTSO) determine tamoxifen sensitivity in ERalpha-positive breast cancer through regulation of BRCA1. PLoS Genet. 2017;13(10):e1007031.

42. Ingle JN, Liu M, Wickerham DL, Schaid DJ, Wang L, Mushiroda T, Kubo M, Costantino JP, Vogel VG, Paik S, et al. Selective estrogen receptor modulators and pharmacogenomic variation in ZNF423 regulation of BRCA1 expression: individualized breast cancer prevention. Cancer Discov. 2013;3(7):812-25.

43. Thewes $V$, Simon $R$, Hlevnjak $M$, Schlotter $M$, Schroeter $P$, Schmidt $K$, Wu $Y$, Anzeneder T, Wang W, Windisch $P$, et al. The branched-chain amino acid transaminase 1 sustains growth of antiestrogen-resistant and ERalphanegative breast cancer. Oncogene. 2017;36(29):4124-34.

44. Jacob J, Favicchio R, Karimian N, Mehrabi M, Harding V, Castellano L, Stebbing J, Giamas G. LMTK3 escapes tumour suppressor miRNAs via sequestration of DDX5. Cancer Lett. 2016;372(1):137-46.

45. Xu Y, Zhang H, Nguyen VT, Angelopoulos N, Nunes J, Reid A, Buluwela L, Magnani L, Stebbing J, Giamas G. LMTK3 represses tumor suppressor-like genes through chromatin remodeling in breast cancer. Cell Rep. 2015;12(5):837-49.

46. Luo L, Tang H, Ling L, Li N, Jia X, Zhang Z, Wang X, Shi L, Yin J, Qiu N, et al. LINC01638 IncRNA activates MTDH-Twist1 signaling by preventing SPOPmediated c-Myc degradation in triple-negative breast cancer. Oncogene. 2018; 37:6166-79.

47. Gu J, Wang Y, Wang X, Zhou D, Shao C, Zhou M, He Z. Downregulation of IncRNA GAS5 confers tamoxifen resistance by activating miR-222 in breast cancer. Cancer Lett. 2018;434:1-10.

48. Zhuo W, Kang Y. Lnc-ing ROR1-HER3 and Hippo signalling in metastasis. Nat Cell Biol. 2017;19(2):81-3.

49. Anbarasu K, Jayanthi S. Identification of curcumin derivatives as human LMTK3 inhibitors for breast cancer: a docking, dynamics, and MM/PBSA approach. 3 Biotech. 2018;8(5):228.

50. Sarma H, Mattaparthi VSK. Structure-based virtual screening of high-affinity ATP-competitive inhibitors against human lemur tyrosine Kinase-3 (LMTK3) domain: a novel therapeutic target for breast cancer. Interdiscip Sci. 2018. https://doi.org/10.1007/s12539-018-0302-7.

51. Sukhatme VP, Cao XM, Chang LC, Tsai-Morris CH, Stamenkovich D, Ferreira PC, Cohen DR, Edwards SA, Shows TB, Curran T, et al. A zinc fingerencoding gene coregulated with c-fos during growth and differentiation, and after cellular depolarization. Cell. 1988;53(1):37-43.

52. Khachigian LM, Lindner V, Williams AJ, Collins T. Egr-1-induced endothelial gene expression: a common theme in vascular injury. Science. 1996; 271(5254):1427-31.

53. Lawson CA, Yan SD, Yan SF, Liao H, Zhou YS, Sobel J, Kisiel W, Stern DM, Pinsky DJ. Monocytes and tissue factor promote thrombosis in a murine model of oxygen deprivation. J Clin Invest. 1997;99(7):1729-38.

54. Yan SF, Zou YS, Gao Y, Zhai C, Mackman N, Lee SL, Milbrandt J, Pinsky D, Kisiel W, Stern D. Tissue factor transcription driven by Egr-1 is a critical mechanism of murine pulmonary fibrin deposition in hypoxia. Proc Natl Acad Sci U S A. 1998;95(14):8298-303.

55. Kubosaki A, Tomaru Y, Tagami M, Arner E, Miura H, Suzuki T, Suzuki M, Suzuki $H$, Hayashizaki Y. Genome-wide investigation of in vivo EGR-1 binding sites in monocytic differentiation. Genome Biol. 2009;10(4):R41.

56. Zagurovskaya M, Shareef MM, Das A, Reeves A, Gupta S, Sudol M, Bedford MT, Prichard J, Mohiuddin M, Ahmed MM. EGR-1 forms a complex with YAP-1 and upregulates Bax expression in irradiated prostate carcinoma cells. Oncogene. 2009;28(8):1121-31.

57. Mou Z, You J, Xiao Q, Wei Y, Yuan J, Liu Y, Brewer G, Ma WJ. HuR posttranscriptionally regulates early growth response-1 (Egr-1) expression at the early stage of T cell activation. FEBS Lett. 2012;586(24):4319-25.

58. Ezer D, Zabet NR, Adryan B. Homotypic clusters of transcription factor binding sites: a model system for understanding the physical mechanics of gene expression. Comput Struct Biotechnol J. 2014;10(17):63-9. 